\title{
Managing White-Collar Work: An Operations-Oriented Survey
}

\author{
Wallace J. Hopp \\ Ross School of Business, University of Michigan, Ann Arbor, Michigan 48109, whopp@bus.umich.edu
}

Seyed M. R. Iravani

Department of Industrial Engineering and Management Sciences, Northwestern University, Evanston, Illinois 60208 iravani@iems.northwestern.edu

Fang Liu

Management Science Group, Merrill Lynch, Global Wealth Management, Pennington, NJ 08534, efangliu@gmail.com

\begin{abstract}
A lthough white-collar work is of vast importance to the economy, the operations management (OM) literature has focused largely on traditional blue-collar work. In an effort to stimulate more OM research into the design, control, and management of white-collar work systems, this paper provides a systematic review of disparate streams of research relevant to understanding white-collar work from an operations perspective. Our review classifies research according to its relevance to white-collar work at individual, team, and organizational levels. By examining the literature in the context of this framework, we identify gaps in our understanding of white-collar work that suggest promising research directions.
\end{abstract}

Key words: white-collar work; operations management; survey

History: Received: July 2006; Accepted: May 2008, after 2 revisions.

\section{Introduction}

Operations management $(\mathrm{OM})$ is concerned with the processes involved in delivering goods and services to customers (Hopp and Spearman 2000, Shim and Siegel 1999). At the core of many of these processes is the work of human beings. Indeed, the field of OM has its roots in the labor efficiency studies of Frederick W. Taylor and other champions of the Scientific Management movement of the early 20thcentury. Because these early studies focused on the physical tasks in manufacturing, construction, and other industries, the OM field developed a tradition of studying what we colloquially call "blue-collar" work. The dramatic improvements in direct labor productivity over the past several decades suggest that this line of research has been highly effective.

However, in recent years, the US economy has steadily shifted toward service and professional jobs that we associate with "white-collar" work (Spohrer and Maglio 2008). Workers in such jobs now constitute $34 \%$ of the workforce according to the Bureau of Labor Statistics (BLS) (Davenport et al. 2002). Furthermore, according to the BLS, workers in "management, business, and financial occupations" and in "professional and related occupations" will increase by $14.4 \%$ and $21.2 \%$, respectively, from 2004 to 2014, which ranks them as the third and first fastest growing occupation categories. ${ }^{1}$ This trend suggests that future economic growth will depend much more on improving productivity of white-collar work than on achieving further improvements in blue-collar work productivity.

Despite the obvious importance of white-collar work to the economy, it is much less understood in an operations sense than is blue-collar work. Well-known principles of bottleneck behavior, task sequencing, line balancing, variability buffering, and many others (Askin and Goldberg 2002, Hopp and Spearman 2000) help us evaluate, improve, and design systems involving blue-collar work. But in systems where white-collar work predominates, in which tasks are less precisely defined and controlled than in blue-collar systems, we do not yet have principles for guiding operations decisions. Fundamental questions remain unanswered. For example: What is the bottleneck of a white-collar work system? What are appropriate measures of productivity? How do learning and collaboration affect performance? To answer these and many other questions, the OM field needs to expand its scope and methods to facilitate 
operations analyses of systems in which white-collar work is an essential component.

A variety of fields, beyond OM, including Economics, Sociology, Marketing, and Organizational Behavior, have produced streams of research relevant to whitecollar work. While these have not focused on operations issues directly, research in these fields has yielded useful insights that could be useful in operations contexts. In this paper, we survey a wide range of research that offers promise for understanding the operations of white-collar work. Our objectives are to bring together these disparate threads, provide a framework for organizing them, and identify needs and opportunities for developing a science of white-collar work.

\section{Definition of White-Collar Work}

To achieve these objectives we must first define what we mean by white-collar work. Historically, the term "white collar" has been used loosely to refer to salaried office workers, in contrast with hourly "blue-collar" manual laborers (Shirai 1983). ${ }^{2}$ Other definitions of white- and blue-collar work are based on whether the worker performs manual work. For example, Prandy et al. (1982) used the term "white collar" to refer to non-manual labor, e.g., supervisors, clerks, professionals, and senior managers. Still other definitions of white-collar work have focused on job categories. For example, Coates (1986) divided whitecollar work into three categories: clerical, professional, and managerial. Because of the nature of the work, some scholars have equated white-collar workers with knowledge workers (McNamar 1973, Ramirez and Nembhard 2004). In this vein, Stamp (1995) summarized eight important aspects of white-collar work: (1) surfacing and aligning values and vision, (2) thinking strategically, (3) focusing key resources, at the same time maintaining flexibility, (4) managing priorities, (5) measuring performance, (6) accepting ownership, responsibility, and accountability, (7) influencing, while maintaining interpersonal awareness, and (8) continually improving people, products, and processes.

Although these definitions give a general sense of what constitutes white-collar work and how it differs from blue-collar work, they do not provide a precise or consistent statement that we can use to focus research on the operations of white-collar work. For example, Coates (1986) classified clerical work, such as typing, as white-collar work. However, typing does not have any of the eight features of white-collar work as defined in Stamp (1995). Moreover, from an operations perspective, typing has much more in common with machining (commonly thought of as "blue collar") than with management (commonly thought of as "white collar"). To study the operations aspects of white-collar work, we need a definition that distinguishes white- and bluecollar work in operationally meaningful ways.
To do this, it is important to recognize that all individuals do many types of work. Indeed, some researchers have argued that new technologies have transformed work in such a way that traditional distinctions between white- and blue-collar workers have been rendered obsolete (Barley and Kunda 2001, Zuboff 1988). Management practices, such as empowerment and self-directed teams, have given even the most basic physical workers decision making responsibility, while information technology (IT) has given virtually every job an element of knowledge work. However, while it may no longer make sense to classify workers as blue and white collar, we believe there remains a fundamental distinction between the two types of work at the task level. The routine, repetitive, largely physical tasks that were the basis of traditional blue-collar work are still essentially different from the non-routine, individual, heavily knowledge-based tasks we associate with traditional white-collar work. Consequently, we focus on the tasks involved in the work (e.g., financial consulting, operating machine tool) rather than on the workers (e.g., financial advisors, machine tool operators).

Viewed in this way, someone we customarily think of as blue-collar worker may perform white-collar tasks (e.g., a machinist brainstorms methods for improving the yield of his operation). Conversely, someone we normally think of as a white-collar worker may perform blue-collar tasks (e.g., a professor makes her own photocopies). Hopp and Van Oyen (2004) defined a task as a process that brings together labor, entities, and resources to accomplish a specified objective. In this very general definition, labor refers to workers (e.g., machinist, doctor, cashier, banker). An entity represents the job being worked on (e.g., part, patient, customer, financial transaction). Resources include anything used by labor to carry out the activity of the task, such as equipment (e.g., machines, computers), technology (e.g., algorithms, systems infrastructures), and intellectual property (e.g., books, reports, outside expertise).

A task is defined by these three elements - labor, entities, and resources - as well as the processes that describe how they are brought together. For our purposes, whether a task is classified as blue or white collar depends on how it is characterized along two dimensions:

1. Intellectual vs. Physical: White-collar tasks involve significant use of knowledge in generating ideas, processes or solutions (Davenport and Prusak 2002), while blue-collar tasks consist primarily of physical transformations or transactions. In these terms, a data analysis task is intellectual because the worker must select and/or develop appropriate models specific to each different case by 
drawing on his/her expertise, statistical knowledge, and prior experience. In contrast, moving a batch of parts from one machine to another in a factory is a physical task that does not require a high level of knowledge. Note that it is the lack of an extensive knowledge component, more than the presence of a large amount of physical labor, that leads us to classify a task as "physical" in nature. For instance, we regard the task of a cashier ringing up groceries as physical, even though the amount of physical effort is not large, because the key steps (scanning items, bagging them, and transferring money) are indeed physical activities for which knowledge requirements are low due to the simple and standardized nature of the work.

2. Creative vs. Routine: White-collar tasks often rely on generation of novel solutions or combination of previously unrelated ideas (Davenport and Prusak 2002, Perry-Smith and Shalley 2003, Shalley 1995), while blue-collar tasks consist primarily of repetitive application of known methods to familiar situations. For example, developing a new drug is a creative task because researchers must visualize new solutions and experiment with unfamiliar alternatives. In contrast, sewing garments is a routine task because it involves repetition of the same actions on each garment. In general, if procedures can be clearly specified in advance, then the task is routine. If procedures cannot be pre-specified, so that it falls to the worker to develop them, then the task is creative. This implies that tasks in the same domain may be classified differently. For example, in surgery, hernia operations may be routine, while advanced transplant operations may be creative.

To provide a reasonable correspondence with the colloquial use of the terms "blue collar" and "white collar," we define a blue-collar task to be one that is mainly physical and routine. Any task that is either highly intellectual or highly creative, we define as white collar. We illustrate this definition in Figure 1, with some examples of types of work that involve tasks characterized by different positions in this two-dimensional space.

It is important to point out that, under this definition, there is no such thing as a pure blue-collar or pure white-collar work (Ramirez and Nembhard 2004).

Figure 1 White-Collar Work vs. Blue-Collar Work

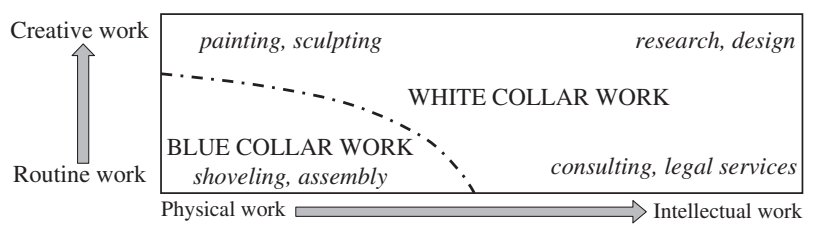

Virtually any type of work consists of some whitecollar tasks and some blue-collar tasks. For example, driving a lift truck to move heavy parts from one part of the factory to another is generally considered to be blue-collar work. However, while the task of driving a lift truck is mainly physical and routine, the driver must sometimes use his creativity to figure out how to efficiently load and unload large items with irregular shapes. So we classify the task of driving parts from point A to point B as a blue-collar task, but classify the task of finding a way to efficiently load and unload new or unusual parts as a white-collar task. Under our definition, all workers, whether they are conventionally thought of as white or blue collar, do both whiteand blue-collar work (Drucker 1999). Because, as OM scholars, we are interested in the efficiency of operations, we are more concerned with classifying and analyzing tasks than with classifying people. Models of white-collar tasks are the foundation for developing an operations understanding of white-collar work.

The above definition raises the question of how white-collar work is related to service work. One might be tempted to classify all service work as whitecollar work because it does not involve heavy physical activity. For example, the activities of a bank teller consist of tasks that do not involve significant work in the physics sense. However, these tasks (e.g., entering a transaction into the computer, counting out cash, etc.) are physical transactions that are not highly knowledge intensive. So, as tasks they are more accurately classified as physical than intellectual. Moreover, they are also highly routine. Hence, in our framework, many of the tasks performed by a bank teller qualify as blue-collar work. We feel that this is appropriate, because from an operations standpoint, the work of a bank teller has far more in common with that of an assembly line worker than it does with that of a lawyer or consultant.

A second distinction that is worth making is that between white-collar work and knowledge work (Davenport et al. 2002). In our definition, knowledge work is considered to be a subset of white-collar work, because highly knowledge-intensive tasks (e.g., legal analysis) are classified as white collar. But there are tasks (e.g., sculpting, composing pop songs) that are creative but not necessarily knowledge intensive. Therefore, knowledge work represents a large portion, but not all, of white-collar work. Note that we include creativity as part of our definition of whitecollar work not because we believe that there are a large number of tasks that are creative but not intellectual, but rather because creative behavior is distinct from intellectual behavior. The literature on creativity, and the management policies for stimulating it, is different from the literature on knowledge-based work and the associated policies for promoting it. 
Hence, having a creativity dimension in our framework will help us identify existing research and future research opportunities that are important to understanding the operations of white-collar work.

Finally, we note that there is nothing absolute about our definitions of blue- and white-collar tasks, or even the terms themselves. Other scholars may be inclined to refer to the type of work we are classifying as "white collar" as "post-industrial" (Barley and Kunda 2001) or "knowledge work" (Davenport 2005). The labels are not important, but the facts that (a) there is a type of work that differs significantly from traditional production work and (b) this type of work has been largely ignored in the OM literature are important. As for our particular framework, we take solace in the familiar adage that "all models are wrong, but some are useful." While we do not claim that our definition of white-collar work is true in any rigorous sense, we do contend that it can help OM scholars identify promising research opportunities and results from other fields that may be helpful in addressing them.

With our definition of white-collar work in hand, we follow the standard OM approach used to model bluecollar work systems by starting with a simple structure, such as single-class job, single-server (e.g., simple produce-to-order system) and extending the analysis to more complex structures, such as multi-class, multipleserver systems. To do this, we state generic models at the individual, group, and organization levels and use these as the organizing framework for our summary of research relevant to white-collar work. This allows us to compare and contrast issues in white- and blue-collar work systems in Sections 3, 4, and 5. By noting which aspects of the generic models have not been well studied in the literature, we are able to suggest promising avenues of future research in Section 6. We summarize our overall conclusions in Section 7.

Before we begin our survey, we note that covering all aspects of white-collar work systems, which could include issues as diverse as public policy, education, urban development, etc., in a single paper is clearly impossible. To keep our scope manageable, we restrict our goals to: (1) identifying key streams of research that are relevant to an operations understanding of white-collar work, and (2) highlighting important papers within each stream that will help direct $\mathrm{OM}$ scholars to useful sources of literature for extending OM research to address important aspects of whitecollar work.

\section{White-Collar Work at the Individual Level}

The simplest context in which to study white-collar work is that of a single person carrying out tasks independently. Examples include a doctor treating a patient, a scientist writing a research paper, and a lawyer preparing a case. Although many studies in the OM literature have addressed systems that involve individual work (Buzacott and Shanthikumar 1993, Hopp and Spearman 2000), these often implicitly combine workers with equipment by assuming "workers are not a major factor," "people (i.e., workers) are deterministic and predictable," "workers are stationary," and "workers are emotionless" (Boudreau et al. 2003). While such assumptions may be oversimplifications in blue-collar settings, they are completely unrealistic in white-collar systems because whitecollar tasks involve knowledge and/or creativity, as well as human characteristics like learning, emotion, and judgment. So representing these is a key step in modeling white-collar work.

\subsection{A Basic Model}

To provide a conceptual framework for representing individual work, we return to the basic representation of a task in Hopp and Van Oyen (2004), which depicts tasks in terms of labor, entities, and resources. Because we are talking about work at the level of an individual, the labor in these systems consists of a single worker. The entities are the logical triggers of tasks. These could be outside requests (e.g., demands from the boss, customer calls for service) or internally generated items (e.g., an idea for a research paper, a plan for improving a system). The resources could include a broad range of physical (e.g., pen, paper, computer) and informational (e.g., books, web sites, personal knowledge, outside expertise) elements. Finally, a fourth element that describes an individual work system is the set of processes that govern the interactions among the labor, entities, and resources in order to complete tasks. These could include sequencing/scheduling rules, incentive policies, and a variety of management directives. The outcome of the work system (e.g., a surgery, a consulting report) will have some value that can be measured soon after completion of a task (e.g., patient recovery status, customer satisfaction), plus possibly some latent value that cannot be measured until well after completion of a task (e.g., increased future effectiveness of members of the surgical team, problem solving tools that may be useful in future consulting jobs). We illustrate this individual work system schematically in Figure 2.

Note that this model highlights both some similarities and some key differences between white- and blue-collar work systems. Similarities stem from the fact that both systems exhibit queueing behavior, in which entities pile up awaiting attention from a worker with finite capacity. This means that variability and high utilization will cause congestion (see 
Figure 2 A White-Collar Work System at the Individual Level

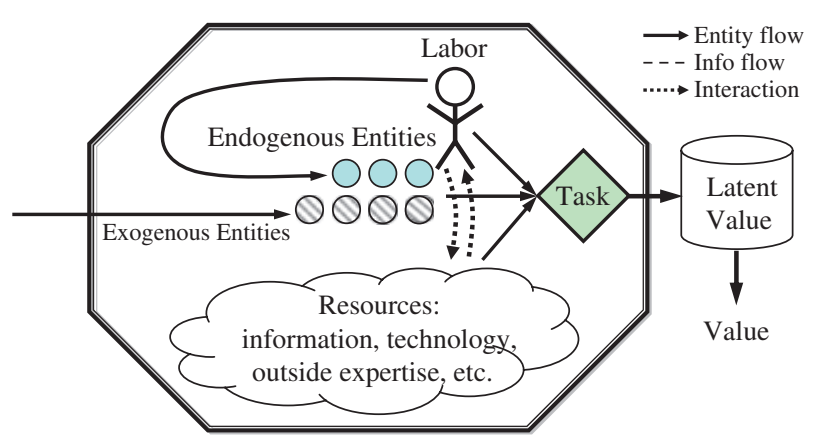

Hopp and Spearman 2000 for a discussion). But there are important differences, including:

1. By our definition of white-collar work, the tasks themselves are of an intellectual and/or creative nature. Workers must accumulate more domain knowledge to carry out white-collar tasks than to perform blue-collar tasks. For example, a risk analyst must master a body of knowledge in order to understand, formulate, and analyze risk problems. Moreover, white-collar tasks are rarely identical, which implies that creativity is often important in white-collar work. For example, in addition to assessing risks in familiar settings, a risk analyst must evaluate new risk scenarios, which requires a certain amount of creativity.

2. White-collar work relies more heavily on knowledge-based resources than does blue-collar work (Drucker 1999). While blue-collar tasks may require informational inputs (e.g., an instruction sheet showing how parts should be assembled), the standardized nature of the work implies that these inputs will be relatively simple. In contrast, white-collar tasks, which involve a higher level of intellectual complexity, may rely on general information that must be processed and synthesized by the worker. For instance, a lawyer preparing a case may have to cull through a vast backlog of precedents and select those relevant to the case at hand.

3. Learning is slower and more central in whitecollar systems than in blue-collar systems (Ryu et al. 2005). The complexity of the resources and the novelty of the tasks mean that workers performing white-collar tasks often have more to learn than workers performing blue-collar tasks. While some models of blue-collar work systems involve learning (e.g., by representing workers as growing more productive over time), learning in white-collar systems may be correlated with other things beyond time in the position, such as communication patterns among individuals.
4. Measurement of output is more difficult in white-collar work systems than in blue-collar systems (Drucker 1991, Salemme 1986). In bluecollar systems outputs are primarily physical (e.g., completed assemblies, cleaned hotel rooms, painted houses). As such, their value can be measured immediately upon completion of a task. For example, a machining operation could go directly to a test station where it is checked for quality, so that the value created by the machinist could be measured as the rate of acceptable parts produced per day. But in white-collar systems, outputs often have a knowledge component. For example, a consultant writes up an analysis of a management problem for a client. The value of such outputs is more difficult to measure. Even if client satisfaction (measured via a survey) could be used as a quality measure for the direct deliverables (i.e., the reports), there may be indirect value of the studies. For instance, a consulting job may produce new knowledge that will be valuable to the consulting firm in performing future jobs. These intangible knowledge outputs of white-collar work are particularly difficult to value economically until long after the task has been completed.

5. While white-collar work systems may receive work from outside in a manner similar to bluecollar systems, they are much more likely to also involve self-generated work. This is because blue-collar tasks (e.g., assembling parts, sweeping a floor, ringing up an order on a cash register) generally address specific requests (e.g., customer orders). In contrast, because white-collar tasks involve a higher degree of creativity, it is common for workers to define at least some of their own workload. Examples include a poet turning an idea into a poem and a consultant adding a task to a consulting job to address an issue that was revealed by previous work.

6. Workers tend to have more discretion over processing times in white-collar systems than in blue-collar systems (Hopp et al. 2007a). In bluecollar systems, tasks are well defined and so come with concrete completion criteria. A casting must be machined to specified tolerances, a room must be cleaned to stipulated standards, etc. But in white-collar systems, where work is intellectually complex and/or nonstandard, detailed specifications are difficult to provide. An engineer tasked with solving a design problem has a general idea of what constitutes an acceptable solution. But he/she must use personal judgment to determine when the task is complete; this decision may depend on customer needs, as well as the engineer's backlog of other work. 
Because the amount of time spent on a task is discretionary, system utilization is not exogenously determined in white-collar systems as it is in blue-collar systems. Hopp et al. (2007a) showed that this implies important differences in the operating behavior of blue- and white-collar work systems (see Section 3).

7. Incentives are more critical in white-collar systems than in blue-collar systems (Eisenberger and Armeli 1997). As we mentioned earlier, because white-collar tasks are intellectual and creative in nature, workers are given more autonomy over task processing. This greater flexibility allows for a large variation in work performance, which suggests that incentives can be extremely important in motivating worker behavior. Furthermore, a substantial amount of job satisfaction from white-collar work is gained through non-pecuniary means, such as peer recognition, task complexity, exposure to smart colleagues, opportunity for self-advancement, etc. Hence, different types of incentives may be appropriate in white-collar work settings than in blue-collar settings. Finally, due to the difficulty of measuring performance objectively, whitecollar incentive plans must often be based on subjective measures of performance (e.g., staff evaluations).

Based on our definition of white-collar tasks and the above discussion, some critical aspects of white-collar tasks that are distinctive from blue-collar tasks are: creativity, discretion, learning, performance measures, incentives, and technology. In the following subsections, we summarize streams of research that have addressed these elements.

\subsection{Creativity}

Creativity generally refers to the ability to generate novel ideas or solutions that are appropriate to the context (Amabile 1983a, 1996, Amabile et al. 1996, Barron and Harrington 1981). Early studies of creativity revealed the importance of individual characteristics, such as intelligence, broad interests, intuition, self-confidence, attraction to complexity, etc., to creativity (Amabile 1983b, Barron and Harrington 1981, Gough 1979, Woodman and Schoenfeldt 1989). More recent studies have emphasized the impact of task processes and organizational and social environments on creativity. One school of thought has argued that work contexts, such as task complexity, deadlines, goal orientations, perceived evaluations, and supervisory styles, affect worker motivation and therefore creative performance (Chesbrough 2003, Oldham and Cummings 1996, Shalley 1991, 1995, Shalley et al. 2000). Work from this stream of research suggests that in- creasing job complexity and enhancing supportive supervisory style can improve worker creativity (Oldham and Cummings 1996). Another school of researchers have focused on the process of creativity. Fleming and Marx (2006) argued that creativity is a process of combining existing ideas with new ones. For example, research is a creative process implemented by combining existing disparate knowledge streams. MacCrimmon and Wagner (1994) examined creative process through computer simulation. They proposed a creativity model in which the process of creativity can be further divided into "problem structuring, idea generation, and evaluation." A more prevailing view of creativity is to treat creativity as a consequence of social exchange behaviors. Because this view often is examined in the context of organizations, we will extensively discuss it in Section 5.

From an operations standpoint, creativity in an individual increases the likelihood of self-generated work. This may increase worker utilization, possibly beyond $100 \%$, which means prioritization is a fundamental problem. Creativity may also increase the likelihood of latent value, because ideas are creative work and ideas as outputs tend to pay delayed dividends. However, while creativity is important at the level of an individual, the operations implications of creativity are most pronounced at the team and organization levels because this is where knowledge sharing and collaboration become issues. We will discuss these in Sections 4 and 5.

\subsection{Discretion}

Another core difference between white- and bluecollar work lies in discretion, i.e., a worker's power to make decisions regarding processing time, task quality, task sequences, etc. Lack of prescribed detailed operational rules requires workers to handle tasks with high degree of discretion. For example, a consultant may determine how much time to spend writing a report based on his/her judgment of quality; a doctor may determine when to release a patient based on the patient's health condition. These discretionary decisions are important because spending extra time and efforts may add value to the output by either improving the quality (e.g., spending longer time may produce a better consulting report, Hopp et al. 2007a), increasing the quantity (e.g., a doctor may charge more money for extra service, Debo et al. 2004), or both. Such discretion is less common in blue-collar tasks than in white-collar tasks because blue-collar work is generally straightforward and well defined. Spending extra time beyond a threshold required to complete the task does not significantly change the output. In contrast, in the more complex setting of white-collar tasks, discretion is frequently reflected in task selection, prioritization and scheduling, 
processing time, and output quality. The prevalence of discretion in white-collar work makes it difficult to apply many results from blue-collar research to whitecollar work systems because most of research on bluecollar work systems is built on the assumption that workers are inflexible or have very limited flexibility (Boudreau et al. 2003, Hopp et al. 2007a).

Because task completion criteria in white-collar work settings cannot be specified precisely in most cases, workers must rely on their own judgment to decide when a task is complete because task quality is generally nondecreasing in the amount of time spent on the task; this implies a speed vs. quality tradeoff. Workers must somehow negotiate this tradeoff, taking into consideration the effect on future work. Hopp et al. (2007a) modeled this problem using an infinite horizon dynamic program with an objective to maximize value produced per unit time. They showed that optimal processing speed increases (and hence average task quality declines) as the number of customers waiting for service increases. Debo et al. (2004) also made the connection between work load and discretionary task completion in a capacitated monopoly service system. They modeled the system as a single-server queue with profit as an increasing function of service time spent, and showed the optimal policy is to increase service speed as work load increases.

While discretionary behavior introduces new problems to OM research, it also provides different insights into well-understood problems. A general principle of blue-collar work systems is that increasing worker capacity always reduces system congestion (i.e., the number of tasks waiting for labor attention). However, Hopp et al. (2007a) showed through simulation experiments that increasing worker capacity may result in higher system congestion because it may be optimal to use extra capacity to improve task quality instead of reducing congestion.

\subsection{Learning}

Learning plays a critical role in white-collar work (Argote and Ingram 2000). Because scenarios faced in white-collar environments frequently evolve rapidly, workers must continually learn new things to perform well. Learning has been studied extensively in the form of "learning curves" in blue-collar settings (Arthur 1991, Cross 1983, Roth and Erev 1995, Sutton and Barto 1998). The core idea behind using learning curves in production systems stems from the observation that workers gain speed and quality through repetitive task processing. Hence, learning is essentially treated as a by-product of doing (i.e., learningby-doing). Learning curve theory is well suited to bluecollar work systems because blue-collar work is more routine and stable over time than white-collar work. In white-collar settings, workers rely on ways other than learning-by-doing to gain knowledge because learning in such circumstances is not simply a byproduct of doing (Carrillo and Gaimon 2004, Ryu et al. 2005). Existing literature has touched on different aspects of learning, such as exploitation vs. exploration (Toubia 2006), timing decisions (Ryu et al. 2005), and methods of learning (Pisano 1994, 1996).

Ryu et al. (2005) studied the interaction between timing and form of learning. They used a model that maximizes the total net profit of knowledge acquisition within finite time periods, where net profit is the difference between total payoff from knowledge acquired and the cost incurred during the learning process. The value of knowledge acquired is measured as the product of knowledge depth and knowledge breadth. Total cost is measured by the cost incurred in the three distinct learning processes: learning-by-investment, learning-by-doing, and learning-from-others. The optimization decision is how to allocate efforts among these three learning processes. Their results characterize the impact of seven environmental factors (discount rate of cost, discount rate of payoff, salvage value of knowledge, initial knowledge, number of group members, productivity of learning-by-doing, and others' knowledge) on learning decisions and suggest an optimal strategy for the timing and type of learning. Pisano (1994, 1996) examined the forms of learning through empirical studies. The author found that learning-by-doing and learning-before-doing are effective ways of learning in different knowledge environments. "In environments where prior knowledge is weak, high-fidelity feedback requires experiments in the actual production environment ('learning-by-doing'). In contrast, when reliable theoretical models and heuristics exist, laboratory experiments, simulation, and other forms of 'learning-before-doing' can be productively harnessed" (Pisano 1994).

From an operations perspective, the essential issue with respect to learning is how it affects performance. The research challenge therefore is to use insights like those noted above to construct more sophisticated alternatives to learning curves to model how learning alters performance over time. To be useful, such models must link performance to the more basic elements that go into learning, such as those identified by Ryu et al. (2005).

\subsection{Performance Measures}

A key challenge of studying white-collar work systems is due to the difficulty of measuring work performance (Davenport and Prusak 2002). In bluecollar work, worker utilization, task completion time, output quality, and quantity can be objectively measured, and thus they can be used to specify a number of quantitative performance measures for evaluating 
system performance, including utilization, throughput makespan, failure rate, etc. However, these metrics often do not translate directly to white-collar work because the inputs are much harder to measure. For example, using the number of reports a consultant produces within certain period of time (i.e., the throughput) is hardly appropriate because the quality and complexity of reports may vary greatly. In general because the white-collar tasks performed by a single worker often differ significantly (e.g., a lawyer's cases, a doctor's patients, and a professor's advisees are all unique), it is difficult to establish uniform metrics of productivity or quality. Finally, whitecollar work often has latent value that can only be measured long after the task is completed. In such cases, fair judgment of output quality upon task completion is almost impossible.

In the literature, there have been a number of efforts to devise simple measures for output evaluation. Gillson et al. (2005) measured latent performance of service technicians by copy machine reliability, which is defined as the average number of copies a machine can make between two customer service calls. Loveman and O'Connell (1995) described how Booz Allen and Hamilton (BA\&H) measures partners' performance in multiple dimensions to motivate them to balance their efforts between sales and client service. The company measures non-partners performance via peer review. Several studies have measured the latent value of academic research publications via delayed recognition in terms of citations (Almeida and Kogut 1999, Fleming 2001, Fleming and Marx 2006, Toubia 2006). Fleming (2001) and Fleming and Marx (2006) used the total number of citations each patent receives by other patents within a certain period of time as a measure of research performance. Toubia (2006) used the number of times an idea is mentioned in later discussions as a proxy for performance of idea generation.

Because individuals rarely work entirely alone, individual performance measures are sometimes designed to incorporate interactions with peers. For example, Christensen and Baird (1998) discussed the case of BA\&H who track the number of times a report in their electronic warehousing and delivery system (i.e., Knowledge-On-Line [KOL]) is downloaded and use this to reward the author. Lee and Ahn (2007) compared the role of individual-based and teambased reward systems in promoting knowledge sharing. Using analytical models, they showed that an individual-based reward system is more effective than a team-based reward system provided that it is designed to be dependent on the amount and quality of the shared knowledge.

Ramirez and Nembhard (2004) provided an excellent overview of the literature on productivity measurement in knowledge work. They presented a taxonomy, conceptual models, and methodologies addressing 13 dimensions of performance, including "quantity, economic factors, timeliness, autonomy, quality, innovation/creativity, customer satisfaction, project success, efficiency, effectiveness, responsibility/importance of work, KW's (i.e., knowledge worker's) perception of productivity, and absenteeism." This review reveals that, while researchers have made some progress in approximating or measuring white-collar productivity, there has been relatively little effort devoted to building general system level models based on specific performance measure. Furthermore, as Ramirez and Nembhard (2004) pointed out we still lack methodologies that integrate and cover multiple performance dimensions. Because performance measures are fundamental to OM modeling and analysis, this is a clear research need.

\subsection{Incentives}

Worker incentives have long been a central issue in OM. From the piece work systems of the Scientific Management era to the supply chain contracts of the present day, OM researchers have studied the impact of individual motivation on overall system performance. In white-collar systems, with their high level of worker autonomy and indirect performance measurement, incentives are particularly important and challenging. More specifically, incentives must motivate learning and creativity, direct discretionary decision making, and enhance adoption and application of new technologies.

Because white-collar work is creative and knowledge intensive, incentives for aligning workers' behaviors with organizational goals should focus on motivating creativity and learning behaviors. Research has shown that means of motivation in whitecollar work systems go far beyond financial incentives. Previous studies have revealed that task complexity, deadlines, goal orientations, perceived evaluations, and supervisory styles can all be used to monitor worker behaviors (Chesbrough 2003, Oldham and Cummings 1996, Shalley 1991, 1995, Shalley et al. 2000, Thompson and Heron 2005). Researchers have also shown that non-pecuniary rewards, such as receipt of awards, honorary memberships, and peer recognition, promote worker creativity in a significant manner (Eisenberger and Armeli 1997, Laudel 2001). Furthermore, previous research has suggested that rewards for creativity in previous tasks promote creativity in later tasks and perceived reward for high performance leads to higher perceived self-determination and therefore better performance (Eisenberger and Armeli 1997, Eisenberger and Rhoades 2001, Eisenberger and Shanock 2003).

A critical antecedent to good incentive design is accurate measurement of performance. Although 
sales revenue is often used to measure the performance of sales managers, such an approximation cannot be readily generalized to many other types of white-collar work, especially when the work does not translate directly into financial values and quantity and quality cannot be fairly judged due to the complex nature of the work (e.g., developing a marketing campaign). Moreover, the value of many types of white-collar work may only be partially measurable upon completion. For example, the value of a new product design may be fully understood only after the product has been on the market for some time. Measurement of such latent value greatly complicates worker performance evaluation. As a result, subjective performance measures (e.g., a manager's rating) are frequently used as bases for incentive plan designs (Ishida 2006, MacLeod 2003). Economists have studied incentive plan based on subjective performance measures in repeated games. MacLeod (2003) showed that, when an agent's selfevaluation and the supervisor's evaluation (which are both subjective) are correlated, the optimal compensation is only dependent on the principal's evaluation, although the agent's self-evaluation plays a role in the agent's satisfaction. Subjective measures can also moderate the weakness associated with objective performance measures (Gibbs et al. 2004). In a study of department managers in car dealerships, Gibbs et al. (2004) found that using subjective measures in addition to objective measures positively affects managers' willingness to incur intangible risk, as well as managers' job satisfaction. For more discussion of subjective vs. objective measures, see Bommer et al. (1995).

Another important aspect of incentives in whitecollar work settings is motivation in multi-tasking situations. Workers in white-collar work settings often perform multiple or multi-dimensional tasks. In these environments, it is important to use incentives to direct workers to allocate their efforts in a manner consistent with the goals of the organization. Datar et al. (2001) studied incentive plans that allocate worker efforts among multiple tasks using relative weights when neither efforts devoted to each task nor the total effort can be observed. Using a linear contract and negative exponential utility structure, Holmstrom and Milgrom (1987) showed how optimal weights can be determined and their relationship to workers' sensitivity to performance measures. Lal and Srinivasan (1993) studied incentive issues of a sales force engaged in selling multiple products. The authors examined the case where sales effort can be modified multiple times within an accounting period depending on the status of sales realization. Assuming that sales history is known to both the salesperson and the firm, the authors showed that "products with higher sales effort effectiveness, lower marginal costs and lower uncertainty in the selling process should be accompanied by a higher commission rate." Feltham and Xie (1994) considered the case where a worker has multiple inter-correlated goals and imperfect performance measures. Using the multi-task framework introduced in Holmstrom and Milgrom (1991), the authors showed that performance measurement in a multi-tasking setting must consider both the expected value of each task itself and the correlations among the tasks.

Instead of evaluating the impact of incentive on the absolute value of performance, some researchers have studied the incentive problem from a goal-setting perspective (Locke and Latham 1990, Seijts et al. 2004). Presence of goals have been found to positively affect worker performance (Shalley 1991). Shalley (1995) studied the nature of the effect of goal setting on worker productivity and creativity via experiments and concluded that the presence of creativity goal promotes workers' creativity but impedes their productivity in a complex work setting. Carrillo and Gaimon $(2000,2004)$ compared the impact of different goals on a manager's decision to invest in knowledge acquisition. They investigated two types of goals. The first was a target goal, which requires a target to be met and imposes a cost for exceeding or falling short of the target (i.e., a two-side goal). They made use of a model in which the cost is expressed as a function of the variance and showed that, when the perceived uncertainty is high, the decision maker will allocate more resources to the behavior that causes less uncertainty. The second type of goal considered by Carrill and Gaimon was a threshold goal. The objective is to achieve a result whose expected value is no less than the desired goal (i.e., one-side goal). Their results suggested that when the decision maker perceives high uncertainty in the outcome from her effort, she is more willing to pursue risky behaviors under a threshold goal scheme than under a target goal scheme. These results yield important insights for incentive goal design associated with knowledge acquisition. For additional literature related to goal setting in work environments, see Berger (1972), Berger (1991), Mantrala et al. (1994), Locke and Latham (1990), Locke and Latham (2004), and Locke and Plummer (2002).

Because most studies of incentives focus explicitly on performance, they are well suited to operations analyses. The research challenge is to make use of the behavioral insights (e.g., how the presence of multiple tasks or task uncertainty affects workers' responses to incentives) within models of specific systems (e.g., product development environments involving design engineers, supply chain networks involving salespersons). 


\subsection{Technology}

Technology is a primary resource in many types of white- and blue-collar task processing. Often the motivation to use technology is to address tasks for which humans are not intrinsically well suited. For example, using automated machines to paint cars is a classic use of technology in a blue-collar task, while using computers to run a simulation is a typical use of technology in a white-collar task. The computer revolution has dramatically expanded the range of whitecollar tasks that can benefit from application of IT. Moreover, the Internet and various types of knowledge management systems have placed a vast amount of information at the disposal of knowledge workers (Zack and McKenney 1995). This has resulted in increased processing speed, improved average output, enhanced performance, and more consistent quality (Carrillo and Gaimon 2004, Dvorak et al. 1997, Ebel and Ulrich 1987). IT has also played an important role in blue-collar work, but in such tasks technology is generally either embedded in the equipment itself (e.g., hardware and software needed to produce a windshield) or used to support established tasks (e.g., computers used to store production data). In both cases, the technology stays unchanged throughout the task; that is, no new technology is generated as a result of the task. In contrast, in white-collar work, workers interact with technology in a profound manner (Dewett and Jones 2001). Technology improvement (e.g., more advanced analysis tools) or new technology (Fleming 2001) is often achieved. Furthermore, IT is also widely used to support decision making and help generate more creative solutions. MacCrimmon and Wagner (1994) showed that using software to generate alternative managerial policies by making connections among problems and internal and external environments leads to a greater variety of alternatives and therefore potentially better decision making.

As technology assumes an ever greater role in white-collar work, new issues associated with technology management (e.g., technology acquisition and implementation) will continue to emerge (Gaimon 1997, Napoleon and Gaimon 2004). A related challenge is refining our understanding of the value of output in an IT-enabled knowledge-sharing environment (e.g., the value of contributions to a database or knowledge management system).

In OM studies, technology is typically viewed as an enabling resource. Computers in control systems, video conferencing in geographically separated collaborative design systems, computers in knowledge management systems, etc., are examples of technologies that play important roles in the operations of white-collar work systems. The above insights into how workers interact with technology in complex work environments may help OM researchers develop more realistic models of systems such as these.

\section{White-Collar Work at the Team Level}

In white-collar work settings, tasks often require collective actions by members of teams to achieve designated goals. A team is a social system consisting of two or more people, "which is embedded in an organization (context), whose members perceive themselves as such and are perceived as members by others (identity), and who collaborate on a common task (teamwork)" (Hoegl and Proserpio 2004). A team can also be defined as "(1) a group of employees that is formally established, (2) which is assigned some autonomy (with different intensities and within different organizational areas), and (3) which performs tasks that require interdependence between members (also with different intensities and areas)" (Rousseau and Jeppesen 2006). Representative examples of teams engaged in white-collar work are product development teams, consulting teams, administrative teams, and information system teams (Janz et al. 1997). Teams can be differentiated from organizations by the degree of task interdependence and the degree of reward interdependence. In an organization, people have shared values in general and receive bonuses that are correlated with the success of the firm. But their actions are not closely integrated and their individual success (e.g., who gets promoted) is not highly correlated. In a group assigned to a set of overlapping tasks (e.g., a product development team), members' work is more closely connected, as are their rewards. In a team assigned to a very specific task, the work of individuals is so closely connected as to be almost indistinguishable (e.g., a group of consultants produces a jointly written report, an assembly team puts together a piece of machinery). When this is the case, rewards almost have to be highly correlated (e.g., if the consulting report is a success, the entire team benefits). Hence, it is critical for teams to "develop a sense of shared commitment and strive for synergy among members" (Guzzo and Dickson 1996). For further discussion of important issues related to team management, see Kozlowski and Ilgen (2006) and Bettenhausen (1991) for comprehensive reviews.

While team management in production environments has been extensively studied by economists, sociologists, management specialists, and OM researchers, much less effort has been devoted explicitly to white-collar work systems. Because many white-collar tasks are highly collaborative in nature (e.g., engineers designing a product or consultants performing a study), a team focus is very important for whitecollar work research. 
Because teams consist of individuals, white-collar work in teams involves all the issues we discussed at the individual level. In the rest of this section, we focus on the aspects of team work that are central to a framework for understanding white-collar work in groups. To provide structure for this framework, we begin by introducing a basic model that captures the major operational elements involved when groups of people work together to carry out white-collar tasks.

\subsection{A Basic Model}

Representing white-collar work at the group level requires a model with the same basic elements as the model at the individual level. Workers still receive tasks exogenously and endogenously generate selfwork. They still make use of and contribute to the growth of resources. The workers still have finite capacity, which leads to queueing dynamics. But, unlike the model at the individual level, we must now account for interaction between team members and the effect on system performance. Conceptually, team performance is determined jointly by the capabilities and efforts of individuals and the synergy between team members. At a more detailed level, team effectiveness is influenced by interdependence (including task interdependence, goal interdependence, and reward interdependence) among team members, team behavior (collaboration, trust), team learning, and incentives.

We depict the basic elements of white-collar work at the team level in Figure 3. The main challenge of modeling white-collar work at this level is representing the interactions between team members and their influence on performance. While teams are common in both blue- and white-collar work settings, the nature of interaction is different in the two types of work. In blue-collar work, teams collaborate on welldefined routine tasks without significant knowledge content or creativity requirements. This raises many interesting questions about how to match individuals to each other and to tasks over time (see Hopp and

Figure 3 A White-Collar Work System at the Team Level

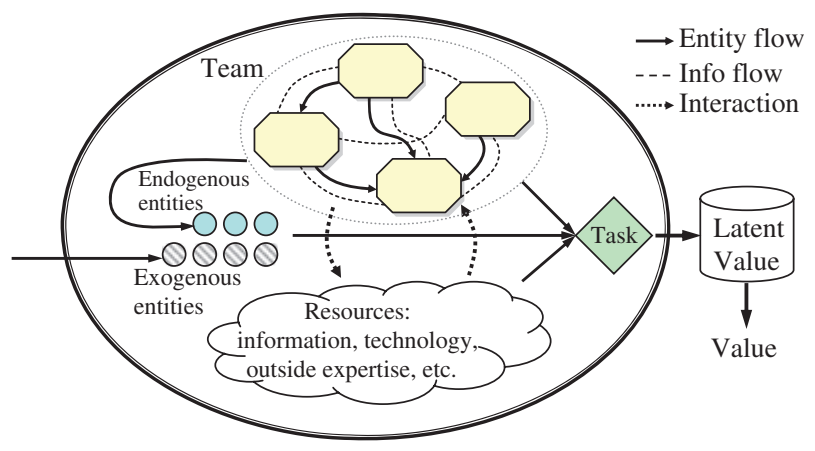

Van Oyen 2004 for a discussion and literature survey). White-collar collaboration goes beyond these to include knowledge sharing aspects of joint work. ${ }^{3}$ Specifically, in addition to issues related to white-collar work at the individual level, at the team level some important issues to consider include:

1. Interdependence among team members is more complex and essential in white-collar work than in blue-collar work (Lengnickhall 1992, Wuchty et al. 2007). Intra-team interdependence exists in both blue- and white-collar work teams but in distinct forms. In blue-collar work teams, due to the well-defined routine tasks, interdependence among team members is simple and explicit. In contrast, in white-collar work teams, workers face complex and loosely defined tasks. Consequently, they rely on frequent interactions with other team members to gain necessary information and work-related knowledge. For example, engineers in design teams exhibit intense interaction, which has been supported in recent years by the proliferation of CAD/CAM technology (Leonard-Barton et al. 1994). In general, interdependence in white-collar work involves much more complex and highly implicit activities, such as knowledge sharing (Argote et al. 1990), than does blue-collar work. Consequently, it is critical to understand and manage intra-team interdependence in order to achieve desirable team performance in white-collar work environments.

2. Behavioral issues, which are important in bluecollar work systems, are paramount, and more highly varied, in white-collar work systems (Dirks 1999, Friedlander 1970). The knowledgebased processing involved in white-collar work calls for a high degree of team synergy to facilitate the collaborations needed in intellectual and creative tasks. Trust, the glue of teamwork, is also vital in white-collar work and therefore must be incorporated into OM studies.

3. Learning is even more critical for effective and efficient team work in knowledge-based whitecollar work than in routine blue-collar work (Haas $2006 a, b)$. Unlike in blue-collar work teams, where team members mainly utilize each other's labor, in white-collar work settings, team members also rely on each other as repositories of knowledge and information. Therefore, team structure, composition, and processes significantly affect knowledge acquisition, dissemination, interpretation, and integration in team work.

4. In white-collar work systems, it is particularly important for team incentives to incorporate elements promoting creativity, knowledge sharing, and repeated collaborations (Guimerà et al. 2005, 
Uzzi and Spiro 2005). As we noted previously, the intellectual and creative aspects of whitecollar work increase the difficulty in measuring work performance objectively and forces incentive schemes to rely on subjective measures. The increased dependence on team members for knowledge, information, and creative ideas further reduces the feasibility of financial incentives. Consequently, effective incentive schemes may require sophisticated psychological bases and a range of dimensions.

In the rest of this section, we summarize existing literature related to interdependence, team behavior, learning, and team incentives.

\subsection{Interdependence}

Intra-team interdependence refers to the extent to which an individual is affected by his/her team members. It plays important roles in predicting team performance (Janz et al. 1997, Van der Vegt and Janssen 2003). For example, team members may foster creativity among each other (Uzzi and Spiro 2005). Interdependence can take various forms, such as task interdependence, goal interdependence, and reward interdependence (Campion et al. 1993). Task interdependence refers to the degree to which an individual depends on other team members' skills and efforts to carry out work effectively and efficiently (Campion et al. 1993, Van der Vegt and Janssen 2003, Wageman 1995, Wageman and Baker 1997). It is a combined result of job design and intra-team interactions. Goal interdependence refers to the degree to which the achievement of one's goal depends on the goal achievement of other team members (Campion et al. 1993, Weldon and Weingart 1993). Reward interdependence refers to the extent to which one's reward depends on other team members' performance (Campion et al. 1993, Wageman 1995, Wageman and Baker 1997).

The research literature has shown that various forms of interdependence affect collaborative behaviors and team performance in different ways. In some cases, they jointly affect performance. For instance, Van der Vegt and Janssen (2003) provided empirical evidence of joint impact of task and goal interdependence. Specifically, they found that, in heterogeneous teams, task interdependence has a strong and positive impact on innovative behaviors when perceived goal interdependence is high, whereas such impact is not found in homogeneous teams. In some other cases, task interdependence has been found to be a significant predictor of collaborative behaviors. For example, Van der Vegt and Van de Vliert (2005) showed in experiments that high skill dissimilarity increases helping behavior in management teams with high task interdependence. Wageman (1995) and Wageman and Baker (1997) studied the interaction between task interdependence and reward interdependence. Wageman (1995) provided empirical evidence that task interdependence promotes collaboration whereas reward interdependence facilitates monitoring of worker effort. Wageman and Baker (1997) found in an analytical model that while both task interdependence and reward interdependence affect performance, increasing task interdependence rather than reward interdependence leads to increased collaboration. They also suggested that higher task interdependence should be accompanied by higher reward interdependence in order to achieve good team performance.

Researchers have used relatively simple measures to represent interdependence. Van der Vegt and Van de Vliert (2005) measured task interdependence in a laboratory experiment setting by the percentage of tasks for which one has to exchange information or cooperate with others. The same type of measurement was also used in Cheng (1983). Wageman and Baker (1997) modeled the degree of task interdependence in a two-worker team as a scalar between 0 and 1 , with a small number indicating one worker's action has little impact on the other's performance and a large number indicating a huge impact. Each worker's performance was then modeled as the weighted average of his own action and the other worker's cooperative action. In a similar fashion, they represented the degree of reward interdependence by a scalar between 0 and 1 . Finally, they modeled a worker's reward as a weighted average of his own performance and team performance, with the degree of reward interdependence being the weight. While these simple representations help model and study the impact of interdependence, our understanding of how to measure interdependence in practice is still very limited. Wageman (1995) provided some examples of measuring interdependence empirically; more comprehensive understanding of this manner is needed.

Both analytic and empirically based representations of the influence of interdependence on team performance could be used in OM studies of white-collar work systems involving teams.

\subsection{Collaboration}

Collaboration is a main activity of all types of teams. A team's collaborative processes may be affected by many behavioral factors, including team members' attitudes, behavior, and emotions (Rousseau and Jeppesen 2006), team members' perception about other members' competence (Kim 2003), and team members' proximity over the duration of the task (Hoegl and Proserpio 2004, Hoegl et al. 2007). Rousseau and Jeppesen (2006) reviewed the impact of three categories of psychological factors - "attitudes, be- 
havior, and emotions" - on team performance. They concluded that "team characteristics such as interdependence and team autonomy, and psychological variables such as cohesion, commitment, procedural justice, and potency are generally positively associated." In addition to psychological factors, researchers have found that team members' perception of other members' competence has a significant impact on team performance (Kim 2003). The reasoning behind this observation is that perceived high competence of other team members may make one feel his/her own contribution is less important and therefore he/she may devote less effort. Kim (2003) showed that the impact of perceived competence of team members is significant and contingent on the amount of task information shared. That is, perceived high competence leads to worse team performance when task information is partially shared, but it leads to better performance when task information is fully shared. Finally, the proximity of team members has been shown to have a strong association with team performance. For reviews of team collaboration, see Hoegl and Proserpio (2004) and Hoegl et al. (2007).

These results provide avenues for incorporating behavioral factors into OM models of team performance.

\subsection{Trust}

Collaboration and team performance are often fundamentally dependent on trust, such that an increase in trust can lead to more collaboration and better team performance (Lewicki et al. 1998, Nooteboom et al. 1997, Sirdeshmukh et al. 2002, Urban et al. 2000). This is particularly true in white-collar work settings because tasks are highly dependent, work processes and outcomes are highly uncertain, and measurement of task outcomes is ambiguous (Singh and Sirdeshmukh 2000). Because team members cannot observe their mates' performance directly, they have no choice but to trust each other if they are to work together effectively. Because of this, research into the concept of trust, impact of trust on team performance, and modeling of the dynamic nature of trust are highly relevant to the operations of white-collar work.

Below, we divide our survey of the broad literature on trust into descriptive studies of the nature of interpersonal trust and prescriptive-oriented research on the operationalization of trust.

4.4.1. Interpersonal Trust. Interpersonal trust among team members can be defined as "the extent to which a person is confident in, and willing to act on the basis of, the words, actions, and decisions of another" (McAllister 1995). As such, trust is a multidimensional construct that can be classified into behavior-based trust and intention-based trust (Mayer 1994). Behavior-based trust refers to the willingness to rely on an exchange partner when that party cannot be controlled or monitored. Intention-based trust may further be classified into competence-based trust and benevolence-based trust. The former refers to the confidence one party has in the other party's capability and reliability (Lieberman 1981), while the latter refers to the confidence one party has in the other party's motives and integrity (Mellinger 1956). Both behaviorand intention-based trust affect team synergy and performance. These constructs of trust have been studied extensively in relational exchange and relational marketing (Crosby et al. 1990, Doney and Cannon 1997, Morgan and Hunt 1994).

Trust is both a predictor and a consequence of interpersonal relationships. Trust is a good predictor of individual behavior and performance. A higher degree of trust leads to greater willingness to engage in risk-taking behaviors (Mayer et al. 1995). Trust also predicts openness, communication, higher level of effort, and reduced conflict within teams (Boss 1978, Dirks 1999, Porter and Lilly 1996, Zand 1972). Hence, an appropriate level of trust implies better group performance (Dirks 1999, Friedlander 1970). However, a high level of trust may also result in reluctance to allow mutual monitoring in self-managing teams, which may hurt team performance when individual autonomy is high (Langfred 2004). In addition to acting as a facilitator of team interaction, trust is also a consequence of teamwork. Empirical studies of multi-stage project teams have shown that trust building is dependent on team performance and that high-performing teams are better at developing and maintaining trust (Kanawattanachai and Yoo 2002). The context and speed of trust building are influenced by the reward structure (Ferrin and Dirks 2003), as well as satisfaction and interpersonal factors, such as expertise and timeliness (Crosby et al. 1990, Morrman 1993) and the strength of interpersonal ties (Fleming and Marx 2006). Other issues related to trust have been explored in the literature on relational exchange and relational marketing (Doney and Cannon 1997, Morgan and Hunt 1994).

4.4.2. Operationalizing Trust. From an OM perspective, it is important to understand how trust can be measured and incorporated into both analytical and behavioral models. There have been some reviews of the existing literature on the measurement of trust (Dietz and Den Hartog 2006, Lewicki et al. 2006). Lewicki et al. (2006) examined the trust development from both behavioral and psychological perspectives (which are organized into four categories based on research approaches, one for behavioral and three for psychological) and answered three major questions in each of the categories: how is trust defined and measured, at what level does trust begin, 
and what factors affect how trust level changes over time. Dietz and Den Hartog (2006) provide a framework for trust measurement and a content analysis of recent empirical measures of trust.

Although there have been many studies on measuring trust, analytic models that explicitly incorporate trust are very limited. The existing literature can be roughly categorized into two schools. One school views trust as unchanged in interactions. For instance, Hwang and Burgers (1997) treated trust as a key component between parties who may benefit from collaborations, but who are also at risk of being taken advantage of if the other party is non-collaborative. They modeled trust as a probability estimation of cooperation by the other party and assumed it remains unchanged throughout the process of collaborations. This enabled the authors to derive some properties of trust in moderating collaborative decision making. An alternative, and more prevalent, view of trust assumes trust to be dynamic and change with interpersonal interactions (Castelfranchi et al. 2003, Hopp et al. 2007b, Melaye and Demazeau 2005, Quercia et al. 2006). This second dynamic school of thought about trust is of particular interest to OM researchers because operations policies, such as flexible work practices and structured teams, may both affect trust levels and be influenced by the nature of trust within the workforce.

Scholars from Computer Science have pioneered the study of trust dynamics. Castelfranchi et al. (2003) used a simulation model to study the interaction between trust and belief. They discussed the role of different belief sources, such as direct experience, categorization, reasoning, and reputation in trust evolution. Melaye and Demazeau (2005) extended the study of belief and trust in a Bayesian framework. The authors examined the impact of direct experience on trust evolution. In their model, trust level is inferred by the truster's basic beliefs, which come from socalled belief sources. Using simulation, the authors showed the impact of positive and negative observations on trust. They also demonstrated that trust may erode in the absence of new experiences.

Although trust is rarely considered in OM studies, some scholars have begun to consider this issue. For example, Loch and Wu (2007) use an experimental approach to demonstrate that social preferences (i.e., intrinsic concern for other parties, which is certainly related to trust) systematically affect supply chain transactions. In particular, such preferences promote cooperation, individual performance, and higher system efficiency than would be predicted by a traditional OM model of strictly self-interested parties. In a similar vein, but using an analytic approach, Hopp et al. (2007b) incorporated trust into a multiperiod supply chain model by modeling trust as a measure of how much a retailer relies on a salesperson's information in demand forecasting. They showed that the retailer's trust in the salesperson leads to improved supply chain performance under different various assumptions about the salesperson's motives.

\subsection{Learning}

White-collar tasks often involve knowledge-based processing, which involves creation, transfer, storage, and utilization of internal and external knowledge. While utilization of internal knowledge is essential, acquisition and application of external knowledge also play important roles in team performance. A team's ability to acquire external knowledge is dependent on properties (e.g., position, tie strength) of the network in which teams are nodes and their work-related communication flows are network ties (Tsai 2001). However, because we will discuss the impact of these properties at the organization level in Section 5, we will focus on team-specific properties (e.g., structural diversity) in the following discussions.

External knowledge generally refers to task-related knowledge, know-how, information, and feedback from outside the team boundary (Haas 2006a). Knowledge acquisition at the team level is affected by team structural diversity (i.e., how different team members are with respect to their affiliations, roles, and positions; Cummings 2004). As diversity increases, team performance due to external knowledge sharing increases because higher structural diversity enables teams to be exposed to more unique external sources. Specialization and related work content also impact the result of learning. Using experiments, Schilling et al. (2003) found that groups working on different but similar tasks over time learn much faster than groups who either are working on specialized tasks or alternate between unrelated tasks. Teams that focus on learn-how instead of learn-what are prone to achieve more implementation successes (Tucker et al. 2006). Knowledge acquisition is also affected by interruptions, such as "encountering novelty, experiencing failure, reaching a milestone, receiving an intervention, coping with a structural change, redesigning the task, or changing authority" ZellmerBruhn (2003). By examining data on operational teams in three firms in the pharmaceutical and medical products industries, Zellmer-Bruhn (2003) found that interruptions enhance knowledge transfer, which in turn improves the acquisition of new team routines. The impact of external knowledge acquisition is contingent on the conditions of knowledge utilization (Haas 2006a). Haas (2006a) found that when team conditions are favorable (e.g., when team members can devote more time to work than the minimum requirement, have more prior work experience, and 
have more collective control over critical decisions), knowledge acquisition enhances team performance in terms of the quality of projects delivered to clients. See Edmondson (2006) for a comprehensive review of team learning.

As at the individual level, the key operational issue regarding learning at the team level is the impact on performance. By characterizing how various behaviors affect learning, the above references provide indirect insights into the factors that affect performance.

\subsection{Incentives}

Just as incentives are critical in promoting work efficiency at the individual level, incentives are vital at the team level in white-collar work settings. In addition to the issues we discussed in the context of individual motivation, a core issue of incentives at the team level is motivation of collaborative behaviors among team members. Specifically, an incentive plan for teams should address issues of team synergy, integrated creativity, and repeated collaborations.

Owing to the difficulty of output measurement in most of white-collar work settings, incentive plans based on subjective measures have also been studied at the team level (Baiman and Rajan 1995, Rajan and Reichelstein 2006). Baiman and Rajan (1995) showed that a discretionary bonus incentive is effective in a two-agent setting. Rajan and Reichelstein (2006) studied a "bonus pool" plan (i.e., the team is informed of how the bonus will be divided based on the realization of noncontractable information). They showed that it is optimal to use a discretionary bonus pool plan when performance can only be measured subjectively. Besides subjective performance measures, another important consideration of team incentives is the impact of repeated interactions among team members. Che and Yoo (2001) studied incentives in a setting of repeated interactions and showed that a joint performance measure (i.e., one in which individual reward is dependent on the performance of others) is desirable because it fosters peer monitoring. Unlike Che and Yoo (2001), who assumed that absolute performance is contractible, Ishida (2006) studied the case where only subjective measures are available and relative team ranking is contractible, and demonstrated the optimality of incentives based on relative performance measures (e.g., awards based on team ranking). This line of research belongs to the literature on relational contracts. For more information, please see Baker (1992) and Baker et al. (1994) for related literature.

Besides team incentives based on financial rewards, research has been devoted to understanding nonfinancial incentives. Guimerà et al. (2005) showed a self-assembly mechanism helps teams gain creativity. Others have suggested that the opportunity of being exposed to new collaborators promotes creative team performance (Uzzi and Spiro 2005). Fleming and Marx (2006) also implied that working with new people provides a level of stimulation not found in solitary work. By working with others, people may gain access to new materials or knowledge that is otherwise unavailable to them. As a result, people enhance their creativity by seeking out new collaborations. For a review of empirical evidence related to the performance of team-based incentives, see DeMatteo et al. (1998).

It is worth mentioning that teams have traditionally been co-located, so that face-to-face interaction comprises the major form of communication among team members (Zack and McKenney 1995). However, as technology advances, new communication channels, such as phone, email, online discussion spaces, and teleconferencing, have made it possible for team members to collaborate at a distance. There is huge literature on virtual teams that studies issues related to these technologies and their impact on team performance. Constrained by the length of the paper, we direct interested readers to Zack and McKenney (1995), Hoegl et al. (2007), and Martins et al. (2004) for more information on this subject.

Although there is a wealth of literature examining trust from various perspectives, there is so far little understanding of how trust affects the operational performance of white-collar work systems. Hence, incorporating insights and modeling techniques from the various streams of the trust literature into $\mathrm{OM}$ models and studies represents a promising area of future research opportunity.

\section{White-Collar Work at the Organization Level}

An organization is a social system in which teams are embedded. As we noted in the previous section, an organization differs from a team in that both the degree of task interdependence and the degree of reward interdependence are relatively low in organizations compared with those in teams. Formally, an organization is made up of multiple individuals and teams. Therefore white-collar work in organizations involves all of the issues noted above for individuals and teams, plus some additional ones. Many of these revolve around communication because this is a much more complex activity at the organization level than at the team level. In teams, shared tasks virtually force communication. But in organizations, many different kinds of communication, both formal and informal, occur. Understanding this communication, how it influences performance, and how it is related to organizational structure and management policy are central concerns in white-collar workforce manage- 
ment. As in the previous sections on white-collar work at the individual and team levels, we first describe a generic model of a white-collar work system at the organizational level and then use it to organize our survey of related streams of research.

\subsection{The Basic Model}

Blue-collar production systems are frequently modeled as flow networks by OM researchers (Hopp and Spearman 2000). This provides a mechanism for linking individual process characteristics (e.g., batching, variability, outages, etc.) to system performance metrics (e.g., throughput, cycle time, cost, quality, etc.). Because organizations performing white-collar work also consist of individual processes (i.e., people) who coordinate to complete tasks, it is appealing to view them as flow networks as well.

Unfortunately, a straightforward translation of the production flow network models to white-collar work settings is not appropriate due to the differences between blue- and white-collar tasks we have discussed earlier. Non-routine intellectual work poses individuals with situations in which they must seek out and acquire useful knowledge dispersed among subunits in the organization (Hansen et al. 1999). Hence, in addition to the work flow, which is formal and direct, there is information flowing among different subunits, which is often informal and complex (Huberman and Hogg 1995).

As shown in Figure 4, a typical organization performing white-collar work consists of multiple subunits, each of which contains a team of one or more workers. Subunits can perform their own tasks, as well as collaborate with other units on more complex tasks. When teams participate in complex task processing, they are linked by either deterministic or probabilistic job flows. These systems can therefore be represented by stochastic networks similar to those used in blue-collar work modeling (Adler et al. 1995). When teams perform independent work in parallel, they can be treated as a single team. They can either solve the problem at hand or seek support from other subunits (e.g., searching and acquiring knowledge) or

\section{Figure 4 A White-Collar Work System at the Organizational Level}

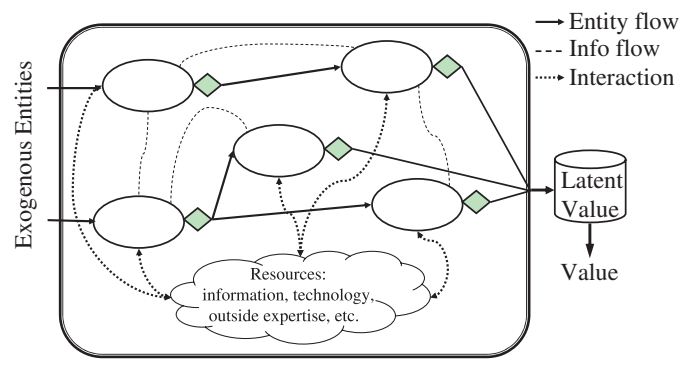

pass it on to another team perceived to be capable of solving the problem.

As shown in Figure 4, a white-collar work system can be viewed in modeling terms as a superimposed network in which informal networks of information flow are combined with a task processing network. This suggests that the following issues are important in studying white-collar work at the organization level.

1. Organizational structures need to address issues created by the knowledge-based processing inherent in most white-collar work (Gokpinar et al. 2008). Because the intellectual and creative content of tasks makes task coordination in whitecollar work settings fundamentally different from that in blue-collar systems, proven methods from blue-collar settings, which rely on standard operating procedures and do not take knowledge and information as inputs, cannot be applied directly to white-collar work systems. Consequently, we need new coordination systems that integrate the knowledge and information elements into the task processing framework.

2. New and more flexible systems are needed to control the flow and assignment of work in white-collar settings (Turner and Makhija 2006). In blue-collar work systems, process control relies largely on standardization and rigid structures (e.g., a pull system used to control a serial production line). However, these control systems are generally ill suited to control white-collar work systems because the intellectual and creative content of white-collar tasks calls for discretion and flexibility. Hence, white-collar work requires methods that recognize and enhance the creative and intellectual components of white-collar work.

3. Organizational learning, which involves knowledge seeking and sharing, has become an increasingly important mechanism by which firms can sustain a competitive advantage (Christensen and Baird 1998, Loveman and O'Connell 1995). Furthermore, because knowledge-based task processing inherent in white-collar work is highly dependent on knowledge and information input (Grant 1996), individuals and teams frequently rely on information and expertise located in and beyond the organization. A great deal of performance variation is due to a lack of information and not being able to access external expertise in a timely fashion. While an organization may formally design its coordination system and create an infrastructure to support organizational learning, knowledge seeking, and sharing largely occur through interactions that are not defined by formal organizational struc- 
tures. Hence, understanding the operations of white-collar work requires an understanding of knowledge seeking and sharing via informal channels.

In the remainder of this section, we review previous research related to the critical issues of structure, control systems, and learning.

\subsection{Structure}

Knowledge-based task processing is embedded in established organizational structures and communication patterns (Sosa et al. 2003). The most widely studied organizational structures in white-collar work environments are hierarchical, modular, and network structures, as we discuss below.

5.2.1. Hierarchical Structures. Classic centralized coordination is characterized by hierarchical organization structures, which have pyramidal forms. Many white-collar work systems are coordinated with such structures. For example, risk management in investment banking is hierarchical, in which each unit of the firm determines its portfolio of risk activities and the overall level of risk is controlled by the risk managers (Vayanos 2003).

Garicano (2000) and Garicano and Rossi-Hansberg (2006) studied the optimal organizational structure in the situation where heterogeneous agents face heterogeneous tasks. Heterogeneity among agents is defined according to their different level of knowledge. An agent can handle a task only when her knowledge level exceeds that required for task processing. If an agent fails to solve a task, he/she may choose to acquire knowledge at some cost or to search for help from other agents with a communication cost represented by the reduced production time. Garicano (2000) showed that the optimal structure for such organizations is a knowledge hierarchy, in which the knowledge of each level is non-overlapping and the size of each level decreases as the knowledge level increases. Garicano and RossiHansberg (2006) extended Garicano's findings to characterize the organizational structure by positive sorting (i.e., "higher ability agents share their knowledge with higher ability subordinates") and skill stratification (i.e., "individuals are segmented by cognitive skills").

Motivated by portfolio formation in investment banks, Vayanos (2003) studied a hierarchical procedure of information processing when communication must occur along hierarchical lines and local information processing by workers is pervasive. Assuming aggregation incurs information loss, Vayanos (2003) showed that in this highly stylized environment, the optimal organizational structure has all workers have a single subordinate and all workers but one work at their full capacity.

While these studies provide us valuable insights into organizing knowledge-based processing hierarchies, they are limited in two aspects. First, they have ignored the interaction among workers at the same level in performing tasks. Second, and more importantly, they do not account for the fact that smart people often ignore formal hierarchies because they know that centralized management frequently stifles thinking and hinders diversity of ideas (Goffee and Jones 2007).

While using rigid hierarchical structures as the basis of operations models of organizational performance may be too unrealistic to be directly applicable to practice, such models may be useful as baselines for comparison with more realistic structures in order to gain insight into the importance of organizational structure on operational performance.

5.2.2. Modular Structures. A modular organization is a loosely coupled system consisting of elements that independently perform distinct functions (Pil and Cohen 2006, Sanchez and Mahoney 1996) and is an effective means of organizing complex and flexible work systems (Baldwin and Clark 2000). Research has found that modularity enhances a firm's capability by allowing greater processing flexibility, which improves its fitness in a dynamic environment (Pil and Cohen 2006). For example, firms may provide a larger variety of product or services through recombinations (Thomke and Reinertsen 1998). Modularity also promotes a firm's sustained competitive advantage by enabling it to adapt more quickly and act on opportunities more effectively (Pil and Cohen 2006). Because of these advantages, white-collar work is often organized in modules. Product development teams are a prototypical example of such structure. But because modules can be formed and combined in many ways, this leaves the question of what is the best module structure for a given organization. Moreover, performing tasks assigned to modules often require interactions beyond the boundaries of individual modules. Because of this, a common problem found in modular organization is that they can limit the interdependence among modules and thereby hinder innovation (Fleming and Sorenson 2001). For an extensive discussion on modularity, see Sanchez and Mahoney (1996).

5.2.3. Network Structure. In most white-collar work systems "the critical input in production and primary source of value is knowledge" (Grant 1996). Production requires coordination of individuals and teams possessing different expertise (Dewatripont and Tirole 2005, Grant 1996). Formal hierarchies and 
modular structures often fail to promote the timely communication and effective collaborations required for good performance. As a result, informal networks (where nodes represent workers and links depict relations among workers; Burt 2004, Cross and Borgatti 2006, Cummings 2004) have been found embedded in many organizations.

One form of network that has been found to characterize the communication/relation structure in many white-collar settings is the small-work network (Watts and Strogatz 1998). For example, this structure has been observed among actors and scientists (Uzzi and Dunlap 2005). Small-world networks are characterized by high clustering (i.e., the probability a friend's friend is a friend) and small diameter (i.e., the average minimum number of steps between any two nodes) (Watts 2004, Watts and Strogatz 1998, Uzzi and Spiro 2005). Clustering reflects local density and diameter reflects separation (Uzzi and Spiro 2005). The short average path length implies that information may flow quickly between different clusters and therefore enhance creativity by allowing combination of disparate knowledge. Meanwhile, high clustering allows local sharing and collaboration. See Watts (2004) for a review of the characteristics and applications of small world networks.

To date, there have been few OM applications of structured networks, such as small world networks. A probable reason for this is that most social network studies do not include explicit performance metrics. However, it is possible to use purely descriptive network models (i.e., without a performance metric) in OM studies. For example, Iravani et al. $(2005,2007)$ made use of structured networks, e.g., small world networks, to characterize the ability of call center agent cross-training structures to respond effectively to variability in call arrival and call process times.

However, most operations studies require models with explicit performance metrics. One way to introduce performance into network analyses of operations systems is to use network measures as dependent variables in empirical studies. An example of this approach is the work of Gokpinar et al. (2008) who studied an organization engaged in vehicle design. They used two related networks to characterize this white-collar work system: a product architecture network, which describes physical and logical connections between vehicle subsystems, and an organization network, which describes communication among design engineers via a formal notification and approval system. Using statistical analysis, the authors showed that engineers who are highly central in the organization network are less likely to generate defective work than are noncentral engineers, but are also slower in meeting task deadlines (due to high utilization). They also compared the organization network and the product architecture network and found that the mismatches (for which they define a quantitative measure called "coordination deficit") are significantly correlated with warranty repair problems. In a related study, Sosa et al. (2003) compared the product architecture and development organization networks for a commercial aircraft engine and identified factors that may prevent alignment of the two networks.

Other authors have sought insight into the impact of network structure on performance by using analytic models. One approach is to characterize how worker interactions influence the evolution of network structure. For example, Huberman and Hogg (1995) studied the dynamics of network structure using a hint model. Hints are ideas that have potential value to the receiver and are shared among workers. Under their model, in each period workers, who perform a multi-step task, choose either to work alone or use a hint sent by others. The value of a hint is dependent on both the content of the hint and how fresh it is to the receiver. Network links change as the interaction pattern alters. Nasrallah and Levitt (2001) used a similar framework of hint sharing to examine how timely access affects the probability of successful interaction. These studies are particularly relevant to the OM field because their use of a flow representation makes them analogous to the flow models prevalent in production and supply chain research.

Many other researchers have examined the formation and evolution of organizational networks that result from decentralized decision making. Rather than pursuing a dynamic view of the network structure, those works have focused on understanding the stable network structure in equilibrium (Bala and Goyal 2000a, b, Galeotti and Goyal 2007, Galeotti et al. 2006, Jackson 2008, Jackson and Watts 2002, Jackson and Wolinsky 1996, Watts 2004). These studies generally model a set of individuals (players), who make decisions concerning link formation by weighing the tradeoff between the cost and the benefit of making a connection. Networks form and evolve as a result of individuals exploiting their network position; that is, local decisions lead to globally emergent behavior. Common features of these models are: (1) individuals are heterogenous; (2) link formation is costly; and (3) an individual's benefits from a connection depends on both the connections of oneself and the connections made by others (Goyal 2007). The results from these studies generally describe the network structure that arises and contrast this emergent network structure with a socially desirable structure. See Jackson (2004) and Goyal (2007) for a review. 
Because these network models of organization structure, communication, and collaboration are well-suited to quantitative analysis and compatible with other network modeling approaches commonly used in the OM field (e.g., network flow models of production systems and supply chains), we believe there is great potential for integrating such models into modeling and analysis of operations systems. We discuss possible directions for modeling research on white-collar work systems that combine work and information flows in Section 6.

\subsection{Control Systems}

Control systems are mechanisms that clearly specify the appropriate methods, behaviors, and outcomes of the system (Turner and Makhija 2006). They generally take one of two forms: process-based control and outcome-based control. Process control, often based on work standardization, is widely used in blue-collar work systems to achieve superior performance. Although some authors have argued that appropriately designed process control can be applied to achieve good performance in some white-collar settings (Nidumolu and Subramani 2003, Turner and Makhija 2006), many white-collar systems are better suited to outcome-based control.

The applicability of process control in white-collar systems depends on the tradeoff between standardization and discretion in processing. Standardization refers to uniform definition of processing methods and/or performance criteria, while discretion involves the flexibility in making decisions or being evaluated based on different standards (Nidumolu and Subramani 2003). Nidumolu and Subramani (2003) examined the role of standardization and decentralization in controlling both white-collar work processes and performance. By studying software development firms, the authors found that combining standardization in performance measures across projects and decentralization in work processes enhances performance. In essence, their approach made it possible to exploit the efficiency of process control, without entirely sacrificing innovation to standardization.

The effectiveness of process control in white-collar settings also depends on the features of the knowledge (e.g., codifiability, completeness, diversity) involved in the tasks (Turner and Makhija 2006). Codifiability refers to the fact that knowledge can be broken down into small and easily understood pieces. When knowledge is highly codifiable, it is relatively easy to break the process and therefore is possible to implement more standardization that facilitate process control. Completeness refers to the degree to which knowledge necessary for task processing is available to the worker. When knowledge is complete, which indicates less uncertainty involved in task processing, a more standardized approach is recommended. Diversity refers to the breadth and relatedness of knowledge. When knowledge is less diversified, more standardization may be applied to process control. In situations where knowledge is non-codifiable, incomplete, or highly diversified, process control may be infeasible and hence outcome control may be the only option.

Another factor that differentiates control systems in white-collar work systems from those in blue-collar systems is information. Because white-collar task processing relies heavily on information, knowledge of information location, direction, and its integration with entity flows is necessary for designing effective control systems. Unlike in blue-collar work systems, where information flow is sequential (i.e., it flows in a predetermined sequence), information flow in whitecollar work systems can be sequential or reciprocal (i.e., it flows back and forth and follows no predetermined sequence) (Egelhoff 1991). Consequently, a control system for a white-collar work system requires more sophisticated information management for storing and sharing formal information, as well as a greater degree of flexibility to allow use of informal information.

The conventional tools of OM are most applicable to systems for which process control is appropriate. Hence, the above studies provide guidance on the types of white-collar work systems that may benefit from both flow-oriented process control and classic OM policies for increasing capacity, reducing congestion, and improving quality.

\subsection{Learning}

Learning is a critical aspect of organization competence. Because white-collar workers often encounter problems that can only be solved with support from others in the organization, the ability to learn (i.e., seek information and share knowledge) is almost always vital to white-collar work performance. For example, Burt (2004) showed that a supply chain manager may be able to produce more good ideas if she shares information and knowledge with other supply chain managers. Huston and Sakkab (2006) found that R\&D workers at Proctor\&Gamble are able to greatly improve their performance by actively sharing information. These knowledge seeking and sharing behaviors are represented in the basic model of Figure 4 as an informal network of informational flow superimposed on a formal task processing network. The entities that flow through the informal network are work-related knowledge and information whose presence may facilitate task processing. Although knowledge seeking and sharing behaviors have become critical to worker performance, there has been little work in the OM community examining 
such behaviors. Hence, we treat seeking and sharing as two distinct procedures and discuss the impact of various factors on these procedures.

Aspects of learning through information seeking has been studied in the literature under the names of exploitation and exploration. Exploitation seeks gradual addition of knowledge and leads to a marginal but certain contribution, while exploration aims to acquire broader and deeper knowledge, and therefore offers a much less certain contribution (Levinthal and March 1993, Toubia 2006). Neither form of learning is without risk. Individuals who are mainly involved in exploitation may fail to acquire needed knowledge, whereas individuals who are exclusively involved in exploration may suffer from obsolescence (Levinthal and March 1993). Hence, maintaining a balance between exploitation and exploration is critical for effective learning. Toubia (2006) studied idea generation with a two-period two-armed bandit model (Bellman 1961) and showed that the choice of strategy (exploitation vs. exploration) is contingent on both the certainty of search and the degree of innovativeness required in the idea.

To discuss knowledge seeking and sharing, we must first distinguish between the different types of knowledge. Based on the difficulty of being codified (Argote and Ingram 2000), knowledge can be classified into two types: tacit and explicit. Tacit knowledge refers to knowledge that is hard or even impossible to codify and therefore is difficult to share through systematic means (Nonaka 1994, Zander and Kogut 1995). In contrast, explicit knowledge is codifiable and can be easily transferred via "formal and systematic language" (Nonaka 1994, Zander and Kogut 1995). With these distinctions in mind, we now survey the literature related to knowledge seeking and sharing.

5.4.1. Knowledge Seeking. Information or knowledge seeking refers to the activities of locating useful information or knowledge sources (Hansen 1999, Morten et al. 2005). The efficiency of knowledge seeking within the organization is affected by the informal networks embedded in formal organizational structures, the networks within teams, and competition within the organization. Examples of such networks are the awareness network (in which a directional tie represents the former has specific knowledge about the latter), the information network (in which a directional tie represents the former seeks help from the latter), and the collaboration network (in which a non-directional tie represents joint work) (Cross and Cummings 2004). The most important properties of networks associated with knowledge seeking are network structure (i.e., node position, number of ties, etc.) and tie strength (i.e., the frequency and intensity of interaction). A larger number of direct connections implies a higher likelihood of locating the right knowledge source and a higher absorptive capacity (i.e., the common knowledge base necessary for absorbing new knowledge) due to past interactions (Hansen et al. 2005) and therefore incurs a lower search cost. However, most research has found that node position, rather than the number of direct ties, is a more significant predictor of searching efficiency. Individuals who occupy positions characterized as "structural holes" or "brokerage positions" are more likely to be exposed to new information and thereby gain timely access to new knowledge more quickly and more frequently (Burt 1992, 2004, Tsai 2001). Besides network structure, tie strength is another important factor affecting search efficiency. Weak ties, referring to distant and less frequent relationships, are efficient for knowledge seeking because "they provide access to novel information by bridging otherwise disconnected groups and individuals in an organization" (Hansen 1999). In contrast, strong ties may impede seeking out new information because people who share strong ties tend to have common friends or tend to have largely overlapped knowledge pools (Granovetter 1978, Reagans and McEvily 2003). Hansen et al. (2005) showed that higher network intensity (i.e., the number of established ties divided by the total number of possible ties) within new product development teams leads to less knowledge seeking from outside the teams. They also showed that greater competition among teams leads to higher sharing cost measured by time spent in communicating and gathering new knowledge.

In addition to understanding knowledge seeking behaviors through empirical or behavioral studies, researchers have also modeled knowledge seeking using analytical models, some of which make use of methodologies used to model blue-collar work system (e.g., queueing theory). These models provide useful insights into issues, such as task and expertise matching, helping and idea utilization, and efficiency of interaction. For instance, Guimerà et al. (2002b) modeled an organization in which heterogeneous tasks and expertise are initially mismatched and tasks need to be delivered to workers with matching expertise. This process is completed via searching and transferring. In their model, the cost of search is proportional to the average distance a task travels before it reaches its destination. In a queueing framework, assuming a task may travel through all possible paths, the authors showed that the congestion (i.e., total task arrival rate) at each node is proportional to the betweenness of the worker (i.e., total number of possible paths a worker occupies) in the informal networks. Guimerà et al. (2002a) considered the same type of organization and incorporated quality of channel into the original model. They modeled the quality of the network tie 
as the geometric average of the capability (a decreasing function of number of tasks currently at the worker) of the sender and receiver, with higher channel quality indicating faster speed. Their results also characterized the relation between network congestion and network structure.

Because these analytic models represent information seeking via flow and queueing frameworks, they are compatible with the flow network approach to modeling task processing that is common in the OM field. As such, they may suggest ways of extending conventional OM models to include organizational learning via knowledge search.

5.4.2. Knowledge Sharing. Knowledge sharing is affected by many factors: the properties of knowledge (i.e., tacitness) (Hansen et al. 1999), the strength of the ties through which knowledge is transferred (Granovetter 1978), absorptive capacity of the recipients (i.e., "prior related knowledge and diversity of backgrounds") (Cohen and Levinthal 1990), mobility of the worker (Almeida and Kogut 1999, Jaffe et al. 1993), knowledge redundancy, and timely access to knowledge source (Huberman and Hogg 1995, Nasrallah et al. 2003). As is knowledge seeking, knowledge sharing is affected by the type of knowledge being transferred. The tacitness of knowledge determines the channel through which knowledge is sought and accumulated. When knowledge is largely tacit, workers rely on complex interactions. For example, Hansen et al. (1999) found that in organizations that provide standard services or products, knowledge is mainly shared in codified form, such as person-to-person interaction. Strong personal ties have been found useful in interpreting and absorbing tacit knowledge. This is because strong ties (i.e., ties maintained through frequent and intensive interactions; Granovetter 1978, Hansen et al. 2005) promote mutual trust and understanding and therefore facilitate complex knowledge sharing (Borgatti and Foster 2003, Burt 1992, 2004, Cross and Borgatti 2006, Fleming and Marx 2006, Granovetter 1978, 1985, Hansen 1999, Krackhardt 1992). Moreover, the recipient's relevant knowledge, experience, and diversity of background also improves sharing effectiveness (Cohen and Levinthal 1990, Szulanski 1996). However, the efficiency of knowledge sharing is constrained by information redundancy and timely access to information sources (Huberman and Hogg 1995, Nasrallah et al. 2003). The occurrence of knowledge sharing may be dependent on worker mobility (Almeida and Kogut 1999). For example, the mobility path of patent holders leads to inter-firm knowledge spillover. For a detailed review of the impact of mobility and research methods using networks, see Brass et al. (2004), Brown and
Duguid (2001), Tsai (2001), Ibarra and Andrew (1993), and Marsden (1990).

Because of the importance of knowledge sharing to organizational learning, it has become common in industry to enhance knowledge sharing among workers via formally designed knowledge exchange systems (Christensen and Baird 1998, Loveman and O'Connell 1995). Loveman and O'Connell (1995) and Christensen and Baird (1998) describe such a system used by BA\&H, called KOL, which is "an electronic warehousing and delivery system that enabled all consultants to access information on industries, technology, markets, and companies that had been generated by prior BA\&H teams." Via this system, knowledge of best practices is shared among consultants, especially junior people, in order to help them do their work more efficiently.

While knowledge sharing is essential to white-collar work, it can become a barrier to performance if not motivated appropriately (Lee and Ahn 2007). One reason is that knowledge sharing is costly. For example, in some cases, people may worry that their work process will be interrupted and therefore may be reluctant to help others when approached for information. In other cases, people may release partial or false information for fear of being outperformed by their peers. Hence, promoting honest and efficient sharing is of great importance to organizations. In the business world, Bain and Company has incorporated how much help a person provides to others into his/her annual compensation (Lee and Ahn 2007). Unfortunately, research in this area is very sparse and our understanding is still very limited.

\section{Research Opportunities}

In Table 1, we summarize the previously reviewed literature deemed relevant to white-collar work at the individual, team, and organizational levels. In addition to organizing the many streams of research by level and topic, this table further breaks these down according to research methodology. As categories of research methodology we use analytical (i.e., using a mathematical model to describe outcomes as a function of various inputs), empirical (i.e., using statistical tools to uncover relationships in observed data), and behavioral/experimental (i.e., using conceptual models of human behavior to understand activities in realworld systems or in controlled experiments). By providing a high-level summary of the coverage in the literature of the key issues involved in understanding the operations of white-collar work, this table provides a platform for identifying promising directions of future research.

Table 1 suggests that considerable research has been done on issues related to white-collar work. But when held against the standard of a coherent science of 
Hopp, Iravani and Liu:: Managing White-Collar Work Production and Operations Management 18(1), pp. 1-32, (C) 2009 Production and Operations Management Society

Table 1 White Collar Work at (a) Individual Level, (b) Team Level, (c) Organization Level

\begin{tabular}{|c|c|c|c|}
\hline & Analytical & Empirical & Behavioral/experimental \\
\hline \multirow[t]{8}{*}{$\begin{array}{l}\text { (a) Individual level } \\
\text { Creativity }\end{array}$} & & Amabile et al. (1996) & Barron and Harrington (1981) \\
\hline & & Shalley et al. (2000) & Amabile (1983a) \\
\hline & & & Woodman and Schoenfeldt (1989) \\
\hline & & & Shalley (1991) \\
\hline & & & MacCrimmon and Wagner (1994) \\
\hline & & & Shalley (1995) \\
\hline & & & Oldham and Cummings (1996) \\
\hline & & & Shalley and Gilson (2004) \\
\hline \multirow[t]{2}{*}{ Discretion } & Debo et al. (2004) & & \\
\hline & Hopp et al. (2007a) & & \\
\hline \multirow[t]{3}{*}{ Learning } & Toubia (2006) & Levinthal and March (1993) & Ryu et al. (2005) \\
\hline & & Pisano (1994) & \\
\hline & & Pisano (1996) & \\
\hline \multirow[t]{5}{*}{ Performance measure } & Ramirez and Nembhard (2004) ${ }^{r}$ & Loveman and O'Connell (1995) & Toubia (2006) \\
\hline & Lee and Ahn (2007) & Christensen and Baird (1998) & \\
\hline & & Fleming (2001) & \\
\hline & & Gillson et al. (2005) & \\
\hline & & Fleming and Marx (2006) & \\
\hline \multicolumn{4}{|l|}{ Incentives } \\
\hline \multirow[t]{5}{*}{ Motivation } & & Oldham and Cummings (1996) & Locke and Latham (2004) \\
\hline & & Laudel (2001) & Gottschalg and Zollo (2007) \\
\hline & & Chesbrough (2003) & \\
\hline & & Thompson and Heron (2005) & \\
\hline & & Davenport et al. (2007) & \\
\hline Subjective & Feltham and Xie (1994) & Gibbs et al. (2004) & Bommer et al. (1995) \\
\hline \multirow[t]{2}{*}{ Measurement } & MacLeod (2003) & & \\
\hline & Ishida (2006) & & \\
\hline \multirow[t]{4}{*}{ Multi-Tasking } & Holmstrom and Milgrom (1991) & & \\
\hline & Lal and Srinivasan (1993) & & \\
\hline & Feltham and Xie (1994) ${ }^{r}$ & & \\
\hline & Datar et al. (2001) & & \\
\hline \multirow[t]{3}{*}{ Goal-Setting } & Carrillo and Gaimon (2004) & Seijts et al. (2004) & Shalley (1991) \\
\hline & & & Shalley (1995) \\
\hline & & & Locke and Plummer (2002) \\
\hline \multirow[t]{2}{*}{ Technology } & Napoleon and Gaimon (2004) & Zack and McKenney (1995) & Dewett and Jones (2001) \\
\hline & Carrillo and Gaimon (2004) & & \\
\hline
\end{tabular}

(b) Team level

Interdependence

Collaboration

Trust
Wageman and Baker (1997)

Hwang and Burgers (1997)

Melaye and Demazeau (2005)

Quercia et al. (2006)

Hopp et al. (2007b)
Leonard-Barton et al. (1994)

Van der Vegt and Janssen (2003)

Uzzi and Spiro (2005)

Kim (2003)

Hoegl and Proserpio (2004)

Hoegl et al. (2007)

Morgan (1995)

McAllister (1995)

Porter and Lilly (1996)

Doney and Cannon (1997)
Weldon and Weingart (1993)

Campion et al. (1993)

Wageman (1995)

Van der Vegt and Van de Vliert (2005)

Rousseau and Jeppesen (2006) ${ }^{r}$

Crosby et al. (1990)

Lewicki et al. (1998)

Lewicki et al. (2006) ${ }^{r}$ 
Hopp, Iravani and Liu:: Managing White-Collar Work

(Continued)

\begin{tabular}{|c|c|c|c|}
\hline & Analytical & Empirical & Behavioral/experimental \\
\hline \multicolumn{4}{|c|}{ (a) Individual level } \\
\hline & & Dirks (1999) & Loch and Wu (2007) \\
\hline & & Kanawattanachai and Yoo (2002) & \\
\hline & & Ferrin and Dirks (2003) & \\
\hline & & Langfred (2004) & \\
\hline \multirow[t]{7}{*}{ Learning } & Edmondson $(2006)^{r}$ & Tsai (2001) & Schilling et al. (2003) \\
\hline & & Hansen (2002) & \\
\hline & & Zellmer-Bruhn (2003) & \\
\hline & & Cummings (2004) & \\
\hline & & Haas (2006a) & \\
\hline & & Haas (2006b) & \\
\hline & & Tucker et al. (2006) & \\
\hline \multirow[t]{4}{*}{ Incentives } & Baiman and Rajan (1995) & DeMatteo et al. $(1998)^{r}$ & Cameron and Pierce $(1994)^{r}$ \\
\hline & Che and Yoo (2001) & Fleming and Marx (2006) & Guimerà et al. (2005) \\
\hline & Rajan and Reichelstein (2006) & & \\
\hline & Ishida (2006) & & \\
\hline
\end{tabular}

(c) Organization level

Structure

$\begin{array}{ll}\text { Hierarchical } & \text { Radner (1993) } \\ & \text { Garicano (2000) } \\ & \text { Vayanos (2003) } \\ & \text { Garicano and Rossi-Hansberg (2006) }\end{array}$

\section{Modular}

Process control

Learning
Network

Knowledge seeking

Knowledge sharing

Huberman and Hogg (1995)

Nasrallah et al. (2003)

Bala and Goyal (2000a)

Iravani et al. $(2005,2007)$

Galeotti et al. (2006)

Galeotti and Goyal (2007)

Huberman and Hogg (1995)

Guimerà et al. (2002b)

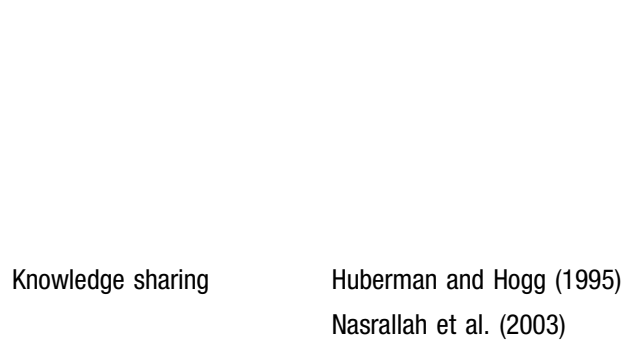

Dirks (1999)

Kanawattanachai and Yoo (2002)

Ferrin and Dirks (2003)

Langfred (2004)

Tsai (2001)

Cummings (2004)

Haas (2006a)

Haas $(2006 \mathrm{~b})$

Tucker et al. (2006)

DeMatteo et al. (1998)

Fleming and Marx (2006) 
white-collar work, this literature is still fragmented and only loosely connected to OM. Furthermore, the various research methodologies have been applied unevenly to important problem areas. For example, knowledge transfer has been studied extensively with empirical methods but analytic models of knowledge transfer processes have been rare. As a result, we have not yet incorporated many important insights from the literature into OM models of white-collar work.

In the following subsections, we use the survey as summarized in Table 1 to highlight some major gaps and suggest research directions that are fundamental to understanding and improving the operations of white-collar work.

\subsection{Performance Measurement}

The ultimate goal of all OM research is to improve the design and management of operations systems. Hence, an essential element of the science of operations for any class of systems is an accurate characterization of performance. This is certainly true for white-collar work systems. Each of the basic models presented above include some form of output process, which could be characterized in terms of value, knowledge, customers satisfaction, or other ways depending on the specific environment. To use these models as frameworks for developing a more concrete understanding of the operations of white-collar work, we need quantitative performance metrics that can be connected to policies.

Unfortunately, accurate measurement of white-collar work output is extremely difficult. "Most traditional HR metrics - such as employee turnover rate, average time to fill open positions, and total hours of training provided cannot accurately predict organizational performance" (Bass and McMurrer 2007). Davenport (2005) suggested that the best way to circumvent this problem is to "Hire smart people and leave them alone." While this might work in some settings, it is hardly a basis for a scientific study of white-collar work.

To develop rigorous performance measures for white-collar work systems, we probably need to look to previous research on blue-collar work systems for inspiration. A number of standard performance measures, including throughput, work in process level, utilization, customer satisfaction, etc., are commonly used to characterize blue-collar work systems. While some of these may translate directly to white-collar settings, many do not. For example, because workers have discretion over the amount of time they spend on a particular task (Hopp et al. 2007a), utilization is a difficult concept to apply in white-collar settings. Indeed, it is quite possible that all white-collar workers in a system are $100 \%$ utilized (e.g., a statistician may seem to work all the time: crunching data in a com- puter, discussing models with peers, etc.). Consequently, the key issue is not how busy workers are, but rather how they allocate their time. New metrics are needed to measure the efficiency and effectiveness with which white-collar workers do this.

Another issue that complicates performance measurement of white-collar work is the latent value of such work. For example, a decision by a manager may have consequences that extend well beyond his/her time as a manager (Feltham and Xie 1994). Because many white-collar tasks are knowledge based, whitecollar work often makes contributions to the knowledge base of the organization, which are difficult to evaluate in the immediate term. However, while latent value is an important feature of white-collar work, we have only seen it examined in empirical studies. There has been almost no effort to model latent value analytically in OM studies. Consequently, we do not yet have means for incorporating latent value of white-collar work into analyses of OMrelated policies, such as incentive plans, prioritization schemes, and collaboration mechanisms.

Even measures that do translate from blue to whitecollar settings may require modification to be useful in white-collar systems. For example, customer satisfaction (Lapre and Tsikriktsis 2006) is appropriate in both blue- and white-collar settings where customer satisfaction can be measured. In blue-collar settings where repetitive products and/or services are provided to customers, simple survey methods can yield reasonable measures of satisfaction. For example, Fornell (2005) measured customer satisfaction at the firm and industry level. But, because important outputs of white-collar work (e.g., contributions to organizational knowledge) are not immediately experienced by customers, many white-collar work systems cannot be reasonably evaluated in customer satisfaction terms. Nevertheless, when a white-collar task is closely connected to a product and/or service, customer satisfaction metrics are key measures of performance. For example, Eisenberger et al. (2007) used customer satisfaction to predict the performance of movie scripts. Straub et al. (1995) studied the role of IT in measuring system usage and integration of objective (i.e., computer-recorded) with subjective (i.e., selfreported) system measures. Research on the collection, analysis, and connection of such metrics to operating policies is essential to the development of a science of white-collar work.

\subsection{Integrated Work and Information Networks}

The OM field has developed a rich literature using network flow models to represent the dynamics of blue-collar work systems (e.g., Buzacott and Shanthikumar 1993, Hopp and Spearman 2000). The flows in such models are physical entities, such as parts, 
jobs, or customers. Such models have also been applied to some white-collar work systems. For example, Adler et al. (1995) applied the idea of network flow models in a module-based project development management. Their findings suggest that some of the basic principles of blue-collar work (e.g., impact of bottlenecks, variability, and flexibility) are applicable to white-collar work that can be represented as network flows. However, research in this area is still sparse and we do not yet have a good understanding of how broadly these principles apply.

However, in knowledge-intensive white-collar work systems, information flows are at least as important as physical flows. Research has shown that information sharing is strongly related to ties among workers, which can range from informal to official (Uzzi 1996, Uzzi and Lancaster 2003). Hence, social network methods offer strong potential for application to OM modeling of systems where information and task processing are embedded in work-related social relationships. Analytic and empirical research into models that integrate social networks into task flow models offers a promising avenue for creating a formal platform for representing white-collar work systems.

A network representation of white-collar work systems raises the issue of how the network is coordinated. In blue work systems, coordination is generally achieved via work process design (e.g., work is organized into a serial production line). In white-collar work settings, however, because information is an important input to knowledge-based processing (Grant 1996), coordination is more complex. For example, a doctor facing an unfamiliar symptom may require advice from more experienced doctors before deciding on a course of treatment. Because the work is less structured than in blue-collar systems, it is not usually practical to impose a rigid structure on the work flow. Hence, white-collar systems must rely on a mixture of centralized control (e.g., a manager makes task assignments and coordinates dynamic adjustments) and decentralized evolution (e.g., workers direct their own search and collaboration activities). Analytic, empirical, and behavioral research into coordination mechanisms is therefore vital to a science of white-collar work operations. Of course, to carry out this research we need the previously discussed performance metrics to represent effectiveness.

Finally, the effectiveness of white-collar work networks is strongly influenced by the flexibility of the constituent workers. It is well known that flexibility is of fundamental importance in blue-collar work system analysis (Gerwin 1993, Sethi and Sethi 1990). Cross-training is an effective way to improve system flexibility because cross-trained workers represent capacity that can be shifted to where it is needed most.
As such, flexibility can result in increased throughput, reduced work-in-process, or improved customer service. In white-collar work systems, most workers perform work in a multi-tasking fashion. For example, a consultant communicates with clients, identifies problems, develops strategies, and helps clients implement management policies to achieve desirable results. A professor teaches, performs research, and advises students. Obviously, flexibility is a prerequisite for such multi-tasking behavior. From a research standpoint, much remains to do to raise our understanding of the role of flexibility in multi-tasking white-collar environments to that we have attained for flow-oriented blue-collar systems.

\subsection{Bottleneck Analysis}

One of the major insights that has come out of network flow analysis of blue-collar work systems is the importance of bottlenecks. Because bottlenecks constrain system capacity, they are fundamental in determining throughput, cycle time, customer service, and other performance metrics. Similar dynamics apply to some white-collar systems. For example, in a multistep software development project, productivity is constrained by the least productive steps regarding both processing speed and output quality. However, bottleneck analyses are seldom used in white-collar systems. The reason is that the standard definition of a bottleneck (i.e., the station with the highest utilization; Hopp and Spearman 2000) may be inappropriate in white-collar work systems because: (a) workers performing white-collar tasks are frequently fully utilized, which invalidates the conventional utilization definition of a bottleneck, (b) output of systems involving white-collar tasks may be constrained by worker capability (e.g., the bottleneck of the R\&D process of skin care and perfume products is the chemists' capabilities of carrying out tests with varying complexity; Balmes and Sosa 2005), which implies that bottleneck definition may be domain specific in white-collar systems, (c) the quality of white-collar tasks can vary greatly, which means that measuring the quantity of tasks completed does not fully capture worker output (e.g., the amount of output is highly sensitive to the worker's discretion on output quality; Hopp et al. 2007a), and (d) output measurement difficulties implied by the knowledge-intensive and nonrepetitive nature of white-collar tasks also dramatically complicates bottleneck analysis. Hence, basic modeling research is needed to develop a white-collar analog to traditional blue-collar bottleneck analysis.

\subsection{Discretionary Decision Making}

A key characteristic of white-collar work systems that distinguishes them from blue-collar systems and complicates modeling and analysis is the high degree of 
discretion in decision making. Task selection, prioritizing, completion, and self-generated work all require discretionary choices on the part of workers. For example, when helping a customer select a car, a salesperson has the freedom to choose which options to recommend and how to price them (within limits). Similarly, the salesperson may choose to speed up processing of current customer if other customers are waiting. Such discretion makes it difficult to predict the behavior of both individual workers and the overall system. Although there has been limited work to model these systems by using a dynamic optimization framework (Hopp et al. 2007a), our understanding of how these systems actually operate in practice is still very limited. To improve the management of discretionary decision making, we need to: (i) identify the areas where discretionary decision making is critical (e.g., task prioritization, time allocation, multi-tasking, information search, etc.) (ii) identify the main factors (e.g., tight deadlines, reward structures, nature of tasks) that impact discretionary decision making, (iii) develop normative models of optimal discretionary decision making in white-collar work settings, and (iv) perform empirical studies of white-collar workers in various environments to determine how they actually make decisions concerning the discretionary aspects of their work and compare these with optimal strategies.

\subsection{Trust}

Trust has always been an important element of the business world. But it is becoming even more vital in the workplace as a result of increased diversity of the workforce, participative management styles, and implementation of work teams (Mayer et al. 1995). Trust plays a critical role in many aspects of white-collar work settings. For example, research has shown that trust affects information sharing (Hopp et al. 2007b), worker effort and mutual monitoring in self-directed teams (Langfred 2004), and supply chain decisions (Johnston et al. 2004, Loch and Wu 2007, Taylor and Plambeck 2007).

However, while trust is of paramount importance to the execution of white-collar work, efforts to incorporate it into OM research have been limited. Hence, there appears to be significant opportunity to incorporate the insights on trust from other fields, such as general management, sociology, and computer science, into OM models and analyses.

The most straightforward avenue would be to investigate how the presence of trust behavior alters decisions (e.g., inventory levels, capacity allocations, work prioritization) relative to those predicted by conventional models based on an assumption of strictly self-serving behavior. A more sophisticated issue is how trust impacts performance of operations systems. This could be manifested in a question as simple as how trust between team members influences their output to a question as complex as how trust between parties affects the effectiveness of standard contracts and the optimal design of (or need for) contracts that explicitly consider trust behavior. Finally, a far reaching research issue is the question of how trust affects the knowledge management aspect of white-collar work, including patterns of knowledge seeking, willingness of workers to share knowledge, and how people weight and use knowledge obtained from their colleagues.

Models that incorporate trust and other social behaviors should give more accurate descriptions of operations systems than the current optimization and equilibrium models used to evaluate a wide range of operations policies (e.g., training, incentives, contracts) and hence may ultimately offer prospects for significantly improving performance of systems involving white-collar work.

\subsection{Learning}

Learning is critical to sustainable competitiveness in both blue-collar and white-collar work systems. Our literature review reveals that there has been a great deal of research examining knowledge seeking and sharing at the organization level. These studies have highlighted how the nature of knowledge (e.g., codifiability, completeness, and diversity; Turner and Makhija 2006), as well as factors such as structural diversity, influence learning through knowledge sharing. However, this research has also noted that knowledge depreciation occurs in white-collar systems, which can have a significant impact on productivity (Park et al. 2006). This is particularly important with respect to technical knowledge (Bosworth 1978, de Holan and Phillips 2004, Park et al. 2006).

The logical starting point for OM research on learning in white-collar work systems would be to try to extend the learning curve approach that has been used for blue-collar systems to knowledge-intensive work environments. That is, we should seek models with which to predict the rate of productivity increase. Given the complexity and knowledge intensity of white-collar tasks, however, we do not expect time in position or number of repetitions, which are typical in blue-collar learning curves, to be sufficient as parameters. Hence, the challenge of this research is to appeal to the literature on learning to identify other factors (e.g., type of knowledge, team diversity, organizational structure) that affect the rate of productivity improvement.

Because the literature on learning identifies communication links and patterns as important drivers of learning, it seems inevitable that models of learning in white-collar settings will rely on networks. At least 
initially, we expect that the most promising methodological approaches will be empirical and experimental research to identify the network characteristics that are most important to learning in specific whitecollar work settings (e.g., product design, consulting, health care, management). But ultimately the goal should be to distill these observations into behavioral assumptions that can be incorporated into the combined work/information flow networks we discussed earlier. The objective of this line of research should be to produce tools that can predict not only the current performance of a white-collar work system, but the evolution of its performance over time as a consequence of institutional learning.

Finally, once we have some basic network models that characterize learning, a host of prescriptive research questions will become amenable to analysis. How to group different types of people in teams to maximize learning, how to rotate people through different job assignments, how many assignments to give individual workers (e.g., assigning a design engineer to multiple products may increase her contact with other engineers and hence speed learning, but may also distract her focus and complicate her time management) are all important management questions that hinge upon an understanding of team and organization learning in white-collar work systems.

\section{Conclusions}

The past several decades have witnessed a dramatic rise in the quantity and variety of white-collar work. The growing need for white-collar research has been addressed by scholars from various disciplines, including Sociology, Organizational Behavior, Marketing, Information Systems, and Economics. Although interest in white-collar work is also on the rise within the OM community, research into operational issues associated with white-collar work is still very limited. Moreover, we lack frameworks for incorporating insights from other fields (e.g., the role of trust, social networks, motivation, learning, knowledge transfer, etc.) into OM models.

In this paper, we have attempted to address these gaps by providing a survey of a range of research streams relevant to white-collar work. We have organized this review by focusing on white-collar work at the individual, team, and the organization levels. To help us classify existing research studies into these categories, we have proposed a basic model for each level of white-collar work. These generic models enable us to connect research from disparate fields to OM concerns. By classifying this research according to topic and methodology, we were able to identify gaps in the research coverage of the key issues involved in understanding white-collar work from an operations perspective and point out specific research opportunities for OM researchers.

We hope that this survey will stimulate fundamental research on white-collar work from an OM perspective and provide a reference for scholars seeking to integrate research threads from different fields to improve our understanding of white-collar work systems.

\section{Acknowledgments}

The authors gratefully acknowledge the support of this work by the National Science Foundation under grant DMI-0423048 and thank the Editor and four anonymous referees for their constructive comments and thoughtful feedback that helped us improve our framework and presentation.

\section{Notes}

${ }^{1}$ http://www.bls.gov/emp/emptab1.htm

${ }^{2}$ The root of these terms is the color of the shirts worn by the workers; office workers traditionally wore white shirts, while laborers wore work shirts that were often blue. Relaxation of professional dress codes and colorful trends in fashion have rendered these terms somewhat anachronistic.

${ }^{3}$ Note that workers we think of as blue collar may also engage in knowledge sharing. For instance, two machinists deciding on the best way to cut a part certainly trade expertise and information. But we would classify such work as a white collar task, because it involves both an intellectual and a creative challenge. This type of situation is why we feel it is important to classify work at the task level, rather than at the occupation level.

\section{References}

Adler, P. S., A. Mandelbaum, V. Nguyen, E. Schwerer. 1995. From project to process management: An empirically-based framework for analyzing product development time. Manage. Sci. 41(3): 435-461.

Almeida, P., B. Kogut. 1999. Localization of knowledge and the mobility of engineers in regional networks. Manage. Sci. 45(7): 905-917.

Amabile, T. M. 1983a. The Social Psychology of Creativity. SpringerVerlag, New York.

Amabile, T. M. 1983b. The social psychology of creativity-A componental conceptualization. J. Pers. Soc. Psychol. 45(2): 357-376.

Amabile, T. M. 1996. Creativity in Context. Westview Press, Boulder, CO.

Amabile, T. M., R. Conti, H. Coon, J. Lazenby, M. Herron. 1996. Assessing the work environment for creativity. Acad. Manage. J. 39(5): 1154-1184.

Argote, L., S. Beckman, D. Epple. 1990. The persistence and transfer of learning in industrial settings. Manage. Sci. 36: 140-154.

Argote, L., P. Ingram. 2000. Knowledge transfer: A basis for competitive advantage in firms. Organ. Behav. Hum. Dec. Process. 82: 150-169.

Arthur, W. B. 1991. Designing economic agents that act like human agents-A behavioral-approach to bounded rationality. Am. Econ. Rev. 81(2): 353-359. 
Askin, R. G., J. B. Goldberg. 2002. Design and Analysis of Lean Production Systems. Wiley, New York.

Baiman, S., M. V. Rajan. 1995. The information advantages of discretionary bonus schemes. Acc. Rev. 70(4): 557-579.

Baker, G. 1992. Incentive contracts and performance measurement. J. Polit. Econ. C: 598-614.

Baker, G., R. Gibbons, K. J. Murphy. 1994. Subjective performancemeasures in optimal incentive contracts. Q. J. Econ. 109(4): 11251156.

Bala, V., S. Goyal. 2000a. A noncooperative model of network formation. Econometrica 68(5): 1181-1229.

Bala, V., S. Goyal. 2000b. A strategic analysis of network reliability. Rev. Econ. Des. 5: 205-228.

Baldwin, C. Y., K. B. Clark. 2000. Design Rules: The Power of Modularity. MIT Press, Cambridge, MA.

Balmes, C., M. Sosa. 2005. R\&d Management at Universal Luxury Group-Perfumes and Cosmetics Division. INSEAD, Fontainebleau, France.

Barley, S. R., G. Kunda. 2001. Bringing work back in. Organ. Sci. 12(1): 76-95.

Barron, F., D. M. Harrington. 1981. Creativity, intelligence, and personality. Annu. Rev. Psychol. 32: 439-476.

Bass, L., D. McMurrer. 2007. Maximizing your return on people. Harv. Bus. Rev. 85(3): 115+.

Bellman, R. 1961. Adaptive Control Process: A Guide Tour. Princeton University Press, Prince, NJ.

Berger, P. D. 1972. On setting optimal sales commissions. Oper. Res. Q. 23: 213-215.

Berger, P. D. 1991. The impact of risk attitude on the optimal compensation plan in a multiproduct situation. J. Oper. Res. Soc. 42: 323.

Bettenhausen, K. L. 1991. Five years of groups research-what have learned and what needs to be addressed. J. Manage. 17(2): 345381.

Bommer, W. H., J. L. Johnson, G. A. Rich, P. M. Podsakoff, S. B. Machenzie. 1995. On the interchangeability of objective and subjective measures of employee performance-A metaanalysis. Personnel Psychol. 48(3): 587-605.

Borgatti, S. P., R. Cross. 2003. A relational view of information seeking and learning in social networks. Manage. Sci. 49(4): 432-446.

Borgatti, S. P., P. C. Foster. 2003. The network paradigm in organizational research: A review and typology. J. Manage. 29(6): 9911013.

Boss, W. J. 1978. Trust and managerial problem solving revisited. Group Organ. Manage. 3(3): 331-342.

Bosworth, D. L. 1978. Rate of obsolescence of technical knowledgenote. J. Ind. Econ. 26(3): 273-279.

Boudreau, J., W. J. Hopp, J. O. McClain, L. J. Thomas. 2003. On the interface between operations and human resources management. Manuf. Serv. Oper. Manage. 5(3): 179-202.

Brass, D. J., J. Galaskiewicz, H. R. Greve, W. P. Tsai. 2004. Taking stock of networks and organizations: A multilevel perspective. Acad. Manage. J. 47(6): 795-817.

Brown, J. S., P. Duguid. 2001. Knowledge and organization: A socialpractice perspective. Organ. Sci. 12(2): 198-213.

Burt, R. S. 1992. Structural Holes: The Social Structure of Competition. Harvard University Press, Cambridge, MA.

Burt, R. S. 2004. Structural holes and good ideas. Am. J. Sociol. 110(2): 349-399.

Buzacott, J. A., J. G. Shanthikumar. 1993. Stochastic Models of Manufacturing Systems. Prentice-Hall, Englewood Cliffs, NJ.

Cameron, J., W. D. Pierce. 1994. Reinforcement, reward, and intrinsic motivation-A metaanalysis. Rev. Educ. Res. 64(3): 363-423.
Campion, M. A., G. J. Medsker, A. C. Higgs. 1993. Relations between work group characteristics and effectiveness-implications for designing effective work groups. Personnel Psychol. 46(4): 823-850.

Carrillo, J. E., C. Gaimon. 2000. Improving manufacturing performance through process change and knowledge creation. Manage. Sci. 46(2): 265-288.

Carrillo, J. E., C. Gaimon. 2004. Managing knowledge-based resource capabilities under uncertainty. Manage. Sci. 50(11): 1504-1518.

Castelfranchi, C., R. Falcone, G. Pezzulo. 2003. Trust in information sources as a source for trust: A fuzzy approach. AAMAS 2003, 89-96.

Che, Y. K., S. W. Yoo. 2001. Optimal incentives for teams. Am. Econ. Rev. 91(3): 525-541.

Cheng, J. L. C. 1983. Interdependence and coordination in organizations-A role-system analysis. Acad. Manage. J. 26(1): 156-162.

Chesbrough, W. H. 2003. A better way to innovate. Harv. Bus. Rev. 81(7): 12-13.

Christensen, C. M., B. Baird. 1998. Cultivating capabilities to innovate: Booz.allen \& Hamilton. Harvard Business Online.

Coates, J. E. 1986. Three models for white collar productivity improvement. Ind. Manage. 28(2): 7-13.

Cohen, W. N., D. A. Levinthal. 1990. Absorptive capacity: A new perspective on learning and innovation. Admin. Sci. Q. 35: 128-152.

Crosby, L. A., K. R. Evans, D. Cowles. 1990. Relationship quality in services selling-An interpersonal influence perspective. J. Mark. 54(3): 68-81.

Cross, J. G. 1983. A Theory of Adaptive Economic Behavior. Cambridge University Press, New York.

Cross, R., S. P. Borgatti. 2006. The ties that share: Relational characteristics that facilitate information seeking. Huysman, M. H., V. Wulf eds Social Capital and IT. MIT Press, Cambridge; 137-161.

Cross, R., J. N. Cummings. 2004. Tie and network correlates of individual performance in knowledge-intensive work. Acad. Manage. J. 47(6): 928-937.

Cummings, J. N. 2004. Work groups, structural diversity, and knowledge sharing in a global organization. Manage. Sci. 50(3): 352-364.

Datar, S., S. C. Kulp, R. A. Lambert. 2001. Balancing performance measures. J. Acc. Res. 39(1): 75-92.

Davenport, T. H. 2005. Thinking for a Living: How to Get Better Performances and Results from Knowledge Workers. Harvard Business School Press, Boston, MA.

Davenport, T. H., L. Prusak. 2002. Working Knowledge: How Organization Manage What They Know. Harvard Business School Press, Boston, MA.

Davenport, T. H., L. Prusak, J. H. Wilson. 2007. Who's bringing you hot ideas (and how are you responding)? Harv. Bus. Rev. 85(3): 24-30.

Davenport, T. H., R. J. Thomas, S. Cantrell. 2002. The mysterious art and science of knowledge-worker performance. MIT Sloan Manage. Rev. 44(1): 23-30.

Debo, L. G., L. B. Toktay, L. N. Van Wassenhove. 2004. Queueing for expert services. INSEAD Working Paper 46(TM), Fontainebleau, France.

de Holan, P. M., N. Phillips. 2004. Remembrance of things past? The dynamics of organizational forgetting. Manage. Sci. 50(11): 1603-1613.

DeMatteo, J. S., L. T. Eby, E. Sundstrom. 1998. Team-based rewards: Current empirical evidence and directions for future research. Group Dyn.-Theory Res. Pract. 20: 141-183.

Dewatripont, M., J. Tirole. 2005. Modes of communication. J. Polit. Econ. 113(6): 1217-1238. 
Dewett, T., G. R. Jones. 2001. The role of information technology in the organization: A review, model, and assessment. J. Manage. 27(3): 313-346.

Dietz, G., D. N. Den Hartog. 2006. Measuring trust inside organisations. Personnel Rev. 35(5): 557-588.

Dirks, K. T. 1999. The effects of interpersonal trust on work group performance. J. Appl. Psychol. 84(3): 445-455.

Doney, P. M., J. P. Cannon. 1997. An examination of the nature of trust in buyer-seller relationships. J. Mark. 61: 307-319.

Drucker, P. F. 1991. The new productivity challenge. Harv. Bus. Rev. 69(6): 69-79.

Drucker, P. F. 1999. Knowledge-worker productivity: The biggest challenge. Calif. Manage. Rev. 41(2): 79-94.

Dupouet, O., M. Yildizoglu. 2006. Organizational performance in hierarchies and communities of practice. J. Econ. Behav. Organ. 61(4): 668-690.

Dvorak, R. E., E. Holen, D. Mark, W. F. Meehan. 1997. Six principles of higher performance it. McKinsey Q. 3: 164-177.

Ebel, K. H., E. Ulrich. 1987. Some workplace effects of cad and cam. Int. Labor Rev. 126(3): 351-370.

Edmondson, A. C. 2006. Three perspectives on team learning: Outcome improvement, task mastery, and group process. Working Paper, Harvard University.

Egelhoff, W. G. 1991. Information-processing theory and the multinational enterprise. J. Int. Bus. Stud. 22(3): 341-368.

Eisenberger, J., S. K. Hui, J. Z. Zhang. 2007. From storyline to box office: A new approach for green-lighting movie scripts. Manage. Sci. 53(6): 881-893.

Eisenberger, R., S. Armeli. 1997. Can salient reward increase creative performance without reducing intrinsic creative interest? J. Pers. Soc. Phychol. 72: 652-663.

Eisenberger, R., L. Rhoades. 2001. Incremental effects of reward on creativity. J. Pers. Soc. Psychol. 81(4): 728-741.

Eisenberger, R., L. Shanock. 2003. Rewards, intrinsic motivation, and creativity: A case study of conceptual and methodological isolation. Creativity Res. J. 15(2-3): 121-130.

Feltham, G. A., J. Xie. 1994. Performance-measure congruity and diversity in multitask principal-agent relations. Acc. Rev. 69(3): 429-453.

Ferrin, D. L., K. T. Dirks. 2003. The use of rewards to increase and decrease trust: Mediating processes and differential effects. Organ. Sci. 14(1): 18-31.

Fleming, L. 2001. Recombinant uncertainty in technological search. Manage. Sci. 47(1): 117-132.

Fleming, L., M. Marx. 2006. Managing creativity in small worlds. Calif. Manage. Rev. 48(4): 6-27.

Fleming, L., O. Sorenson. 2001. The dangers of modularity. Harv. Bus. Rev. 79(8): 20-21.

Fornell, C. 2005. The American Customer Satisfaction Index at Ten Years. Stephen M. Ross School of Business, University of Michigan, Ann Arbor, MI.

Friedlander, F. 1970. Primacy of trust as a facilitator of further group accomplishment. J. Appl. Behav. Sci. 6(4): 387-400.

Gaimon, C. 1997. Planning information technology-knowledge worker systems. Manage. Sci. 43(9): 1308-1328.

Galeotti, A., S. Goyal. 2007. The law of the few. Working Paper, University of Essex.

Galeotti, A., S. Goyal, J. Kamphorst. 2006. Network formation with heterogeneous players. Games Econ. Behav. 54(2): 353372.

Garicano, L. 2000. Hierarchies and the organization of knowledge in production. J. Polit. Econ. 108(5): 874-904.

Garicano, L., E. Rossi-Hansberg. 2006. Organization and inequality in a knowledge economy. Q. J. Econ. 121(4): 1383-1435.
Gerwin, D. 1993. Manufacturing flexibility: A strategic perspective. Manage. Sci. 39(4): 395-410.

Gibbs, M., K. A. Merchant, W. A. Van der Stede, M. E. Vargus. 2004. Determinants and effects of subjectivity in incentives. Acc. Rev. 79(2): 409-436.

Gillson, L. L., J. E. Mathieu, C. E. Shalley, T. M. Ruddy. 2005. Creativity and standardization: Complementary or conflicting drivers of team effectiveness. Acad. Manage. J. 48(3): 521-531.

Goffee, R., G. Jones. 2007. Leading clever people. Harv. Bus. Rev. 85(3): $72+$.

Gokpinar, B., W. J. Hopp, S. M. R. Iravani. 2008. The impact of product architecture and organization structure on the efficiency and quality of complex product development. Working paper, Northwestern University.

Gottschalg, O., M. Zollo. 2007. Interest alignment and competitive advantage. Acad. Manage. Rev. 32(2): 418-437.

Gough, H. G. 1979. Creative personality scale for the adjective check list. J. Pers. Soc. Psychol. 37(8): 1398-1405.

Goyal, S. (2009). Connections: An Introduction to the Economics of Networks. Princeton University Press, Princeton, NJ.

Granovetter, M. 1985. Economic action and social structure: The problem of embeddedness. Am. J. Sociol. 91: 481-510.

Granovetter, M. S. 1973. The strength of weak ties. Am. J. Sociol. 78 1360-1380.

Granovetter, M. S. 1978. Threshold models of diffusion and collective behavior. J. Math. Soc. 9: 165-179.

Granovetter, M. S. 1983. The strength of weak ties: A network theory revisited. Sociol. Theory 1: 201-233.

Grant, R. M. 1996. Toward a knowledge-based theory of the firm. Strategic Manage. J. 17: 109-122.

Guimerà, R., A. Arenas, A. Diaz-Guilera, F. Giralt. 2002a. Dynamical properties of model communication networks. Phys. Rev. E 66(2). Art. No. 026704 Part 2, 026704.1-026704.8.

Guimerà, R., A. Diaz-Guilera, F. Vega-Redondo, et al. 2002b. Optimal network topologies for local search with congestion. Phys. Rev. Lett. 89(24). Art. No. 248701, 248701.1-248701.4.

Guimerà, R., B. Uzzi, J. Spiro, L. A. N. Amaral. 2005. Team assembly mechanisms determine collaboration network structure and team performance. Science. 29: 639-641.

Guzzo, R. A., M. W. Dickson. 1996. Teams in organizations: Recent research on performance and effectiveness. Annu. Rev. Psychol. 47: 307-338.

Haas, M. R. 2006a. Acquiring and applying knowledge in transnational teams: The roles of cosmopolitans and locals. Organ. Sci. 17(3): 367-384.

Haas, M. R. 2006b. Knowledge gathering, team capabilities, and project performance in challenging work environments. Manage. Sci. 52(8): 1170-1184.

Hansen, M. T. 1999. The search-transfer problem: The role of weak ties in sharing knowledge across organization subunits. Admin. Sci. Q. 44: 82-111.

Hansen, M. T. 2002. Knowledge networks: Explaining effective knowledge sharing in multiunit companies. Organ. Sci. 13(3): 232-248.

Hansen, M. T., M. L. Mors, B. Lovas. 2005. Knowledge sharing in organizations: Multiple networks, multiple phases. Acad. Manage. J. 48(5): 776-793.

Hansen, M. T., N. Nohria, T. Tierney. 1999. What's your strategy for managing knowledge? Harv. Bus. Rev. 77(2): 106-116.

Hoegl, M., H. Ernst, L. Proserpio. 2007. How teamwork matters more as team member dispersion increases. J. Prod. Innovation Manage. 24(2): 156-165.

Hoegl, M., L. Proserpio. 2004. Team member proximity and teamwork in innovative projects. Res. Policy 33(8): 1153-1165. 
Holmstrom, B., P. Milgrom. 1987. Aggregation and linearity in the provision of intertemporal incentives. Econometrica 55(2): 303-328.

Holmstrom, B., P. Milgrom. 1991. Multitask principal agent analyses-incentive contracts, asset ownership, and job design. J. Law Econ. Organ. 7(Special Issue): 24-52.

Hopp, W. J., S. M. R. Iravani, G. Yuen. 2007a. Discretionary task completion: A key difference between white-collar and bluecollar work systems. Manage. Sci. 53(1): 61-77.

Hopp, W. J., S. M. R. Iravani, G. Yuen. 2007b. Trust and information sharing in supply chains. Working Paper, Northwestern University.

Hopp, W. J., M. L. Spearman. 2000. Factory Physics: Foundations of Manufacturing Management. 2nd ed. Irwin/McGraw-Hill, Burr Ridge, IL.

Hopp, W. J., M. P. Van Oyen. 2004. Agile workforce evaluation: A framework for cross-training and coordination. IIE Trans. 36(10): 919-940.

Huberman, B. A., T. Hogg. 1995. Communities of practice: Performance and evolution. Comuput. Math. Organ. Theory 1: 73-92.

Huston, L., N. Sakkab. 2006. Connect and develop: Inside Procter \& Gamble's new model for innovation. Harv. Bus. Rev. 84(3): 58-66.

Hwang, P., W. P. Burgers. 1997. Properties of trust: An analytical view. Organ. Behav. Hum. Dec. Process. 69(1): 67-73.

Ibarra, H., S. B. Andrew. 1993. Power, social influence, and sense making: Effects of network centrality and proximity on employee perceptions. Admin. Sci. Q. 38: 277-303.

Iravani, S. M. R., B. Kolfal, M. P. Van Oyen. 2007. Call center labor cross-training: It's a small world after all. Manage. Sci. 53: 11021112.

Iravani, S. M. R., K. Sims, M. P. Van Oyen. 2005. Structural flexibility: A new perspective on the design of manufacturing and service operations. Manage. Sci. 51: 151-166.

Ishida, J. 2006. Team incentives under relative performance evaluation. J. Econ. Manage. Strategy 15(1): 187-206.

Jackson, M. O. 2004. A survey of models of network formation: Stability and efficiency. Demange, G., M. Wooders eds. Group Formation in Economics; Networks, Clubs and Coalitions. Cambridge University Press, Cambridge UK: 11-57.

Jackson, M. O. 2008. Social Networks in Economics. Handbook of Social Economics. Elsevier, Amsterdam.

Jackson, M. O., A. Watts. 2002. On the formation of interaction networks in social coordination games. Econ. Behav. 41(2): 265291.

Jackson, M. O., A. Wolinsky. 1996. A strategic model of social and economic networks. J. Econ. Theory 71: 44-74.

Jaffe, A. B., M. Trajtenberg, R. Henderson. 1993. Geographic localization of knowledge spillovers as evidenced by patent citations. Q. J. Econ. 108(3): 577-598.

Janz, B. D., J. A. Colquitt, R. A. Noe. 1997. Knowledge worker team effectiveness: The role of autonomy, interdependence, team development, and contextual support variables. Personnel Psychol. 50(4): 877-904.

Johnston, D. A., D. M. McCutcheon, F. I. Stuart, H. Kerwood. 2004. Effects of supplier trust on performance of cooperative supplier relationships. J. Oper. Manage. 22(1): 23-38.

Kanawattanachai, P., Y. Yoo. 2002. Dynamic nature of trust in virtual teams. J. Strategic Inf. Syst. 11(3-4): 187-213.

Kim, P. H. 2003. When private beliefs shape collective reality: The effects of beliefs about coworkers on group discussion and performance. Manage. Sci. 49(6): 801-815.

Kozlowski, S. W. J., D. R. Ilgen. 2006. Enhancing the effectiveness of work groups and teams. Psychol. Sci. 7(3) (Suppl. S): 77-124.
Krackhardt, D. 1992. The strength of strong ties: The importance of philo in organizations. Nohria, N., R. C. Ecclas eds. Networks and Organizations: Structure, Form, and Actions. Harvard University Press, Cambridge, MA, 216-239.

Lal, R., V. Srinivasan. 1993. Compensation plans for single-product and multiproduct salesforces-An application of the Holmstrom-Milgrom model. Manage. Sci. 39(7): 777-793.

Langfred, C. W. 2004. Too much of a good thing? Negative effects of high trust and individual autonomy in self-managing teams. Acad. Manage. J. 47(3): 385-399.

Lapre, M. A., N. Tsikriktsis. 2006. Organizational learning curves for customer dissatisfaction: Heterogeneity across airlines. Manage. Sci. 52(3): 352-366.

Laudel, G. 2001. Collaboration, creativity and rewards: Why and how scientists collaborate. Int. J. Technol. Manage. 22(7-8): 762-781.

Lee, D. J., J. H. Ahn. 2007. Reward systems for intra-organizational knowledge sharing. Eur. J. Oper. Res. 180(2): 938-956.

Lengnickhall, C. A. 1992. Innovation and competitive advantagewhat we know and what we need to learn. J. Manage. 18(2): 399-429.

Leonard-Barton, D., K. Bowen, K. B. Clark, C. A. Holloway, S. C. Wheelwright. 1994. How to integrate work and deepen expertise. Harv. Bus. Rev. 72: 121-131.

Levinthal, D. A., J. G. March. 1993. The myopia of learning. Strategic Manage. J. 14(Special Issue): 95-112.

Lewicki, R. J., D. J. McAllister, R. J. Bies. 1998. Trust and distrust: New relationships and realities. Acad. Manage. Rev. 23(3): 438-458.

Lewicki, R. J., E. C. Tomlinson, N. Gillespie. 2006. Models of interpersonal trust development: Theoretical approaches, empirical evidence, and future directions. J. Manage. 32(6): 991-1022.

Lieberman, J. K. 1981. The Litigious Society. New York: Basic Books, New York, NY.

Loch, C. H., Y. Wu. 2007. Social preferences and supply chain performance: An experimental study. Working paper, INSEAD, Fontainbleau, France.

Locke, E. A., G. P. Latham. 1990. A theory of goal setting and task performance. Prentice Hall, Englewood Cliffs, NJ.

Locke, E. A., G. P. Latham. 2004. What should we do about motivation theory? Six recommendations for the twenty-first century. Acad. Manage. Rev. 29(3): 388-403.

Locke, E. A., M. D. Plummer. 2002. Building a practically useful theory of goal setting and task motivation-A 35-year odyssey. Am. Psychol. 57(9): 705-717.

Loveman, G., J. O'Connell. 1995. Booz.Allen \& Hamilton: Vision 2000. Harvard Business Online.

MacCrimmon, K. R., C. Wagner. 1994. Stimulating ideas through creativity software. Manage. Sci. 40(11): 1514-1532.

MacLeod, W. B. 2003. Optimal contracting with subjective evaluation. Am. Econ. Rev. 93(1): 216-240.

Mantrala, M. K., P. S. Murali, A. A. Zoltners. 1994. Structuring a multiproduct sales quota-bonus plan for a heterogeneous sales force: A practical model-based approach. Mark. Sci. 13(2): 121-144.

Marsden, P. V. 1990. Network data and measurement. Annu. Rev. Sociol. 16: 435-463.

Martins, L. L., L. L. Gilson, M. T. Maynard. 2004. Virtual teams: What do we know and where do we go from here? J. Manage. 30(6): 805-835.

Mayer, G. W. 1994. Social information processing and social networks: A test of social influence mechanisms. Hum. Relat. 47: 1013-1048.

Mayer, R., J. Davis, F. Schoorman. 1995. An integrative model of organizational trust. Acad. Manage. Rev. 20(3): 709-734. 
McAllister, D. J. 1995. Affect- and cognition-based trust as foundations for interpersonal cooperation in organizations. Acad. Manage. J. 38: 24-59.

McNamar, T. 1973. White collar job enrichment-pay board experience. Pub. Admin. Rev. 33(6): 563-368.

Melaye, D., Y. Demazeau. 2005. Bayesian dynamic trust model. Multi-Agent Systems and Applications IV. Springer, Berlin/ Heidelberg, 480-489.

Mellinger, G. D. 1956. Interpersonal trust as a factor in communication. J. Abnorm. Soc. Psychol. 52: 304-309.

Morgan, P. 1995. A model of search, coordination, and market segmentation. Revised mimeo, SUNY Buffalo.

Morgan, R. M., S. D. Hunt. 1994. The commitment-trust theory of relationship marketing. J. Mark. 58(3): 20-38.

Morrman, C. 1993. Factors affecting trust in market-research relationships. J. Mark. 57(1): 81-101.

Morten, T. H., L. M. Mors, B. Lovas. 2005. Knowledge sharing in organizations: Multiple networks, multiple phases. Acad. Manage. J. 48(5): 776-793.

Napoleon, K., C. Gaimon. 2004. The creation of output and quality in services: A framework to analyze information technologyworker systems. Prod. Oper. Manag. 13(3): 245-259.

Nasrallah, W. F., R. E. Levitt. 2001. An interaction value perspective on firms of differing size. Comput. Math. Organ. Theory 7: 113144.

Nasrallah, W. F., R. E. Levitt, P. Glynn. 2003. Interaction value analysis: When structured communication benefits organizations. Organ. Sci. 14(5): 541-557.

Nidumolu, S. R., M. R. Subramani. 2003. The matrix of control: Combining process and structure approaches to managing software development. J. Manage. Inf. Syst. 20(3): 159-196.

Nonaka, I. 1994. A dynamic theory of organizational knowledge creation. Organ. Sci. 5(1): 14-37.

Nooteboom, B., H. Berger, N. G. Noorderhaven. 1997. Effects of trust and governance on relational risk. Acad. Manage. J. 40(2): 308338.

Oldham, G. R., A. Cummings. 1996. Employee creativity: Personal and contextual factors at work. Acad. Manage. J. 39(3): 607-634.

Park, G., J. Shin, Y. Park. 2006. Measurement of depreciation rate of technological knowledge: Technology cycle time approach. $J$. Sci. Ind. Res. 65(2): 121-127.

Perry-Smith, J. E., C. E. Shalley. 2003. The social side of creativity: A static and dynamic social network. Acad. Manage. Rev. 28(1): 89106.

Pil, F. K., S. K. Cohen. 2006. Modularity: Implications for imitation, innovation, and sustained advantage. Acad. Manage. Rev. 31(4): 995-1011.

Pisano, G. P. 1994. Knowledge, integration, and the locus of learning-An empirical analysis of process-development. Strategic Manage. J. 15(Special Issue): 85-100.

Pisano, G. P. 1996. Learning-before-doing in the development of new process technology. Res. Policy 25(7): 1097-1119.

Porter, T., B. Lilly. 1996. The effects of conflict, trust, and task commitment on project team performance. Int. J. Conflict Manage. 7(4): 361-376.

Prandy, K., A. Stewart, R. M. Blackburn. 1982. White-Collar Work. Macmillan Press, London.

Quercia, D., S. Hailes, L. Capra. 2006. B-trust: Bayesian trust framework for pervasive computing. Lect. Notes Comput. Sci. 3986: 298-312.

Radner, R. 1993. The organization of decentralized information processing. Econometrica 61(5): 1109-1146.

Rajan, M. V., S. Reichelstein. 2006. Subjective performance indicators and discretionary bonus pools. J. Acc. Res. 44(3): 585-618.
Ramirez, Y. W., D. A. Nembhard. 2004. Measuring knowledge worker productivity. J. Intellect. Capital 5(4): 602-628.

Reagans, R., B. McEvily. 2003. Network structure and knowledge transfer: The effects of cohesion and range. Admin. Sci. Q. 48(2): 240-267.

Roth, A. E., I. Erev. 1995. Learning in extensive-form games: Experimental data and simple dynamic models in the intermediate term. Games Econ. Behav. 8(Special Issue: Nobel Symposium): 164-212.

Rousseau, V., H. J. Jeppesen. 2006. Teamwork and associated psychological factors: A review. Work Stress 20(2): 105-128.

Ryu, C., Y. J. Kim, A. Chaudhury, H. R. Rao. 2005. Knowledge acquisition via three learning processes in enterprise information portals: Learning-by-investment, learning-by-doing, and learning-from-others. MIS Q. 29(2): 245-278.

Salemme, T. 1986. Measuring white collar work. White Collar Productivity Improvement 1524, American Productivity Center.

Sanchez, R., J. T. Mahoney. 1996. Modularity, flexibility, and knowledge management in product and organization design. Strategic Manage. J. 17(Special Issue): 63-76.

Schilling, M. A., P. Vidal, R. E. Polyhart, A. Marangoni. 2003. Learning by doing something else: Variation, relatedness, and the learning curve. Manage. Sci. 49(1): 39-56.

Seijts, G. H., G. P. Latham, K. Tasa, B. W. Latham. 2004. Goal setting and goal orientation: An integration of two different yet related literatures. Acad. Manage. J. 47(2): 227-239.

Sethi, A. K., S. P. Sethi. 1990. Flexibility in manufacturing: A survey. Int. J. Flexible Manuf. Syst. 2(4): 289-328.

Shalley, C. E. 1991. Effects of productivity goals, creativity goals, and personal discretion on individual creativity. J. Appl. Psychol. 76(2): 179-185.

Shalley, C. E. 1995. Effects of coaction, expected evaluation, and goal-setting on creativity and productivity. Acad. Manage. J. 38(2): 483-503.

Shalley, C. E., L. L. Gilson. 2004. What leaders need to know: A review of social and contextual factors that can foster or hinder creativity. Leadership Q. 15(1): 33-53.

Shalley, C. E., L. L. Gilson, T. C. Blum. 2000. Matching creativity requirements and the work environment: Effects on satisfaction and intentions to leave. Acad. Manage. J. 43(2): 215-223.

Shim, J. K., J. G. Siegel. 1999. Operations Management. Barron's Educational Series. Barron's Educational Series, Hauppauge, NY.

Shirai, T. 1983. A theory of enterprise unionism. Shirai, T. ed. Contemporary Industrial Relations in Japan. University of Wisconsin Press, Madison, WI, 117-143.

Singh, J., D. Sirdeshmukh. 2000. Agency and trust mechanisms in consumer satisfaction and loyalty judgments. J. Acad. Mark. Sci. 28(1): 150-167.

Sirdeshmukh, D., J. Singh, B. Sabol. 2002. Consumer-trust, value, and loyalty in relational exchanges. J. Mark. 66(1): 15-37.

Slikker, M., A. van den Nouweland. 2001. Social and Economic Networks in Cooperative Game Theory. Kluwer Academic Publishers, Dordrecht.

Sosa, M. E., S. D. Eppinger, C. M. Rowles. 2003. The misalignment of product architecture and organizational structure in complex product development. Manage. Sci. 50(12): 1674-1689.

Spohrer, J., P. Maglio. 2008. The Emergence of service science: Toward systematic service innovations to accelerate co-creation of value. Prod. Oper. Manag. 17(3): 238-246.

Stamp, D. 1995. The Invisible Assembly Line: Boosting White Collar Productivity in The New Economy. Amacom Books, New York.

Straub, D., M. Limayem, E. Karahannaevaristo. 1995. Measuring system usage: implication for IS theory testing. Manage. Sci. 41(8): 1328-1342. 
Sutton, R. S., A. G. Barto. 1998. Reinforcement Learning: An Introduction. MIT Press, Cambridge, MA.

Szulanski, G. 1996. Exploring internal stickiness: Impediments to the transfer of best practice within the firm. Strategic Manage. J. 17: $27-43$.

Taylor, T. A., E. L. Plambeck. 2007. Simple relational contracts to motivate capacity investment: Price only vs. price and quantity. Manuf. Serv. Oper. Manage. 9(1): 94-113.

Thomke, S., D. Reinertsen. 1998. Agile product development: Managing development flexibility in uncertain environments. Calif. Manage. Rev. 41(1): 8-30.

Thompson, M., P. Heron. 2005. The difference a manager can make: Organizational justice and knowledge worker commitment. Int. J. Hum. Resour. Manage. 16(3): 383-404.

Toubia, O. 2006. Idea generation, creativity, and incentives. Mark. Sci. 25(5): 411-425.

Tsai, W. P. 2001. Knowledge transfer in intraorganizational networks: Effects of network position and absorptive capacity on business unit innovation and performance. Acad. Manage. J. 44(5): 996-1004.

Tucker, A. L., I. M. Nembhard, A. C. Edmondson. 2006. Implementing new practices: An empirical study of organizational learning in hospital intensive care units. Working Paper, Harvard University.

Turner, K. L., M. V. Makhija. 2006. The role of organizational controls in managing knowledge. Acad. Manage. Rev. 31(1): 197-217.

Urban, G. L., F. Sultan, W. J. Qualls. 2000. Placing trust as the center of your internet strategy. Sloan Manage. Rev. 42: 39-49.

Uzzi, B. 1996. The sources and consequences of embeddedness for the economic performance of organizations: The network effect. Am. Sociol. Rev. 61(4): 674-698.

Uzzi, B., S. Dunlap. 2005. How to build your network. Harv. Bus. Rev. 83(12): 53-62.

Uzzi, B., R. Lancaster. 2003. Relational embeddedness and learning: The case of bank loan managers and their clients. Manage. Sci. 49(4): 383-399.

Uzzi, B., J. Spiro. 2005. Collaboration and creativity: The small world problem. Am. Sociol. Rev. 111(2): 447-504.
Van der Vegt, G. S., O. Janssen. 2003. Joint impact of interdependence and group diversity on innovation. J. Manage. 29(5): 729-751.

Van der Vegt, G. S., E. Van de Vliert. 2005. Effects of perceived skill dissimilarity and task interdependence on helping in work teams. J. Manage. 31(1): 73-89.

Vayanos, D. 2003. The decentralization of information process ing in the presence of interactions. Rev. Econ. Stud. 70(3): 667-695.

Wageman, R. 1995. Interdependence and group effectiveness. Admin. Sci. Q. 40(1): 145-180.

Wageman, R., G. Baker. 1997. Incentives and cooperation: The joint effects of task and reward interdependence on group performance. J. Organ. Behav. 18(2): 139-158.

Watts, D. J. 2004. The new science of networks. Annu. Rev. Sociol. 30: 243-270.

Watts, D. J., S. H. Strogatz. 1998. Collective dynamics of 'smallworld' networks. Nature 393: 440-442.

Weldon, E., L. R. Weingart. 1993. Group goals and group performance. Br. J. Soc. Psychol. 32: 302-334.

Woodman, R. W., L. F. Schoenfeldt. 1989. Individual differences in creativity: An interactionist perspective. Glover, J. G., R. R. Ronning, C. R. Reynolds eds. Handbook of Creativity. Plenum, New York, 77-92.

Wuchty, S., B. Jones, B. Uzzi. 2007. The increasing dominance of teams in the production of knowledge. Science, 316: 10361039.

Zack, M. H., J. L. McKenney. 1995. Social-context and interaction in ongoing computer-supported management groups. Organ. Sci. 6(4): 394-422.

Zand, D. 1972. Trust and managerial problem solving. Admin. Sci. Q. 17: 229-239.

Zander, U., B. Kogut. 1995. Knowledge and the speed of transfer and imitation of organizational capabilities: An empirical test. Organ. Sci. 6(1): 76-92.

Zellmer-Bruhn, M. E. 2003. Interruptive events and team knowledge acquisition. Manage. Sci. 49(4): 514-528.

Zuboff, S. 1988. In the age of the smart machine: The future of work and power. Basic Books, New York, NY. 